\title{
Is Uruguay More Resilient This Time? Distributional Impacts of a Crisis Similar to the 2001-02 Argentine Crisis
}

\author{
Oscar Barriga Cabanillas \\ University of California, Davis. USA. \\ obarriga@ucdavis.edu
}

\author{
María Ana Lugo \\ World Bank. USA. \\ mlugo1@worldbank.org \\ Hannah Nielsen \\ World Bank, USA. \\ hnielsen@worldbank.org
}

\author{
Carlos Rodríguez-Castelán ${ }^{1}$ \\ World Bank. USA. \\ crodriguezc@worldbank.org
}

\author{
María Pía Zanetti \\ World Bank. USA. \\ mzanetti@worldbank.org
}

Received: 29 January 2015 / Revised: 31 May 2015 / Accepted: 5 August 2015 / Published online: 17 August 2015

\begin{abstract}
The 2001-02 Argentine crisis had a profound impact on Uruguay's economy. Uruguay's gross domestic product shrank by 17.5 percent, and the proportion of people living below the poverty line doubled in only two years. It took almost 10 years for the poverty rate to recover to its precrisis level. This paper uses a macro-micro simulation technique to simulate the impact of a similar crisis on the current Uruguayan economy. The simulation exercise suggests that Uruguay would now be in a better place to weather such a severe crisis. The impact on poverty would be considerably more moderate; inequality would not change significantly; and household incomes would be 8 percent lower than in the absence of a crisis (almost 9 percent lower among households in the bottom 40 percent of the income distribution). The paper also explores the changes in social welfare policy that took place in the last decade that are protecting vulnerable groups from new macroeconomic shocks. We find that, despite the new policies, young individuals, woman-headed households, residents of Montevideo, and people who have not completed secondary education are more vulnerable to falling into poverty were the crisis to strike.
\end{abstract}

JEL classification: E32, E37, F6, I3, O54

Keywords: Business cycles, microsimulations, distributional analysis, Uruguay 


\section{INTRODUCTION ${ }^{2}$}

Uruguay has experienced remarkable growth and poverty reduction in the last decade and resolved many of the structural issues leading to the severe impact of the 2001-02 Argentine crisis. Debt management reform, improved banking regulations, better social safety nets, and increased export diversification reduced the country's vulnerability. This could be seen during the 2008-09 financial crisis, which led to a significant, but short-lived drop in gross domestic product (GDP), but did not cause a prolonged recession or significant rise in the number of the poor.

Despite macroeconomic stabilization and considerable growth in recent years, however, Uruguay remains exposed to several internal and external risks. The internal challenges relate mainly to the high inflation, coupled with a slowdown in growth and a loss in competitiveness. The trade-off policy makers are facing is between further monetary tightening to bring inflation within the target range without excessively stifling the economy and maintaining the flexible exchange rate regime with an appreciating peso leading to the loss in competitiveness.

Besides the internal challenges, Uruguay is also exposed to shocks from the external environment. Given Uruguay's dependence on Argentina and Brazil as main trading partners, a hard landing in Argentina and less growth in Brazil could have a significant negative impact on Uruguay's economy. Meanwhile, the economy is exposed to changes in commodity prices and foreign direct investment (FDI) inflows resulting from a potentially prolonged Euro area crisis.

The close ties with its neighboring countries and the exposure to their economies were felt during the Argentine crisis at the beginning of the last decade. Between 1999 and 2003, the Uruguayan economy shrank by 17.5 percent in real terms, and household income dropped by over 20 percent (World Bank 2005). The crisis in Argentina led to capital flight, insolvent banks, depleted reserves, high sovereign debt, and soaring inflation in Uruguay and also caused a major decline in production and exports from Uruguay as well as a significant drop in private and government consumption. At the same time, moderate poverty in the country surged, climbing to close to 40 percent in 2003-04 from only 15 percent in 1999.

The objective of this paper is therefore to assess the impact of a severe crisis similar to the 2001-02 Argentine crisis on the current Uruguayan economy. The questions this analysis attempts to answer are the following: (1) Given the significant reforms during the last decade, is Uruguay now better placed to weather a severe crisis? (2) What will be the impact of such an event on poverty, shared prosperity, and overall income distribution? (3) Given that a large share of the population has exited poverty in recent years, how vulnerable is this population segment? How likely are these people to fall back into poverty? As an alternative scenario, the paper also assesses the impact of a crisis similar to the crisis of 2008-09, which was transmitted through different channels relative to the 2001-02 crisis.

The paper is organized as follows: Section 2 introduces the methodology underlying the simulations carried out for this analysis. Section 3 outlines the country context. This is followed by a description of the macroeconomic assumptions beneath the scenarios in section 4 . Section 5 presents the simulation results. Section 6 concludes.

The authors would like to thank Sergio Olivieri for his indispensable advice and contributions and Louise Cord, Marina Gindelsky, Sarah Kotb, Zafer Mustafaoglu, Mary Alexander Sharman, Augusto Tano Kouame and two anonymous referees for their thoughtful comments and suggested edits. The authors would also like to thank the participants at a workshop on microsimulation techniques in Montevideo in April 2013 for helpful observations and recommendations. The views, findings, and conclusions expressed in this paper are entirely those of the authors and do not necessarily reflect those of the World Bank, its Executive Board, or member country governments. 


\section{METHODOLOGY}

The microsimulation model is based on a simplified version of the approaches developed by Bourguignon, Bussolo, and Pereira da Silva (2008) and Ferreira et al. (2008). As outlined in Habib et al. (2010a, 2010b, 2010c), the method models the way macroeconomic shocks are transmitted to the labor market through (1) losses in employment and labor earnings and (2) losses in nonlabor incomes through declines in international remittances. The microsimulation combines macro level information on the projected growth of output, employment, remittances, labor earnings, population, and prices with micro level information on labor and nonlabor income, labor force status, and basic job characteristics. ${ }^{3}$

The microsimulation model involves three basic steps: (1) benchmarking, (2) simulation, and (3) impact assessment. The first step uses household- and individual-level information to model labor market behavior and the receipt of remittances. Labor force status is divided into six categories and is modeled as a function of household and individual characteristics. ${ }^{4}$ Parameters are estimated by means of a multinomial logit estimation as in Ferreira et al. (2008). Labor earnings for all employed individuals are then modeled as a function of individual and job characteristics, and parameters are estimated by means of a Mincerian ordinary least squares regression. An assignment rule for remittances is then modeled nonparametrically.

Using the estimations obtained in the baseline step, the second step simulates the process by which macro level changes - projections of population growth, labor force status and earnings, and international remittances - are translated into changes in the labor market and into labor and nonlabor income at the micro level. This simulation step is divided into four stages. First, demographic changes between the base year - 2011 - and the year of the crisis are adjusted to replicate projections of population growth. Second, aggregate flows between employment and unemployment as well as across sectors of employment are used to project labor force status and earnings at the micro level using the multinomial logit and the Mincerian ordinary least squares estimations from the baseline step. Third, the assignment rule for remittances is followed to allocate aggregate changes in remittances at the micro level. Fourth, minimal assumptions are used to simulate changes in other sources of nonlabor income.

The model simulation relies on a series of assumptions to make microeconomic data consistent with macroeconomic projections, using behavioral estimations from precrisis household economic data to predict future economic outputs. In this sense, besides the obvious need for reliable macroeconomic data at the sectoral level, the model requires a series of assumptions to be satisfied. The first assumption is that the structural relationships underlying the assignment of employment to each sector remain constant, that is, the conditions that determine employment in a specific sector are not affected by the crisis. Additionally, the model assumes that the growth rates of labor income and profits are the same as the aggregate product rates in each sector, that the factors of production are immobile, and that price changes occur only between food and nonfood items.

The final step of the microsimulation exercise is to assess the impact of a possible crisis by generating new income distributions. These distributions allow one to compare the crisis and the no-crisis scenarios. This step includes adjusting the poverty line to account for changes in food prices, constructing measures of per capita household income, and evaluating the poverty and distributional impact of the crisis using the distribution of income under both scenarios.

\footnotetext{
A recent module of the ADePT software has been developed for microsimulations: the ADePT simulation module, which has been used for all the microsimulations in this paper. See the ADePT cirsis module, ADePT: Software Platform for Automated Economic Analysis (database), World Bank, Washington, DC, http://go.worldbank.org/UDTL02A390.

4 The categories are inactive, unemployed, and employment in the following four sectors: the primary sector (agriculture, fishing, and mining); manufacturing (including electricity, gas, water, and construction); commerce, tourism, and transport; and other services (financial and government services).
} 
Household data as well as macroeconomic data are needed. The major data needs for the exercise are, at the household level, labor force surveys with detailed information on the distribution of the working-age population by sector and economic status as well as earnings. At the macro level, ideally, good projections for the key macro variables under the two scenarios (benchmark and post-policy reform) are needed (projections of population growth, labor market composition and earnings, and international remittances).

\section{COUNTRY CONTEXT}

\subsection{Macroeconomic developments}

Uruguay was hit hard by the 2001-02 Argentinean crisis, but recorded a strong macroeconomic performance over the following years. Uruguay's economy experienced a deep recession, with negative growth rates of real GDP of up to 7.7 percent in 2002, high inflation, and significant debt accumulation (figures 1 and 2). Following the crisis, however, the economy recovered, and real GDP growth averaged more than 5 percent a year beginning in 2003, marking one of the longest growth periods in the country's history. Prudent macroeconomic policies, improvements in structural areas, and favorable external economic conditions, such as buoyant demand for the main export products and a booming regional economy, contributed to the strong economic performance of Uruguay and helped protect the economy during the 2008-09 crisis.

Figure 1

Real GDP growth rates, 2000-12

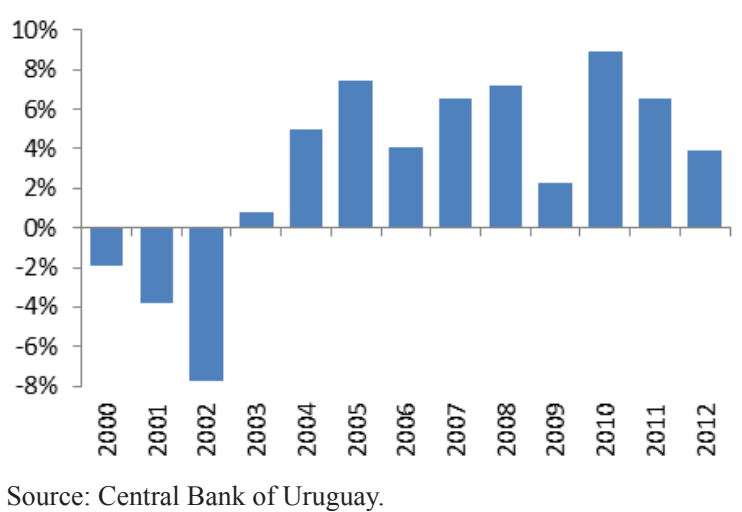

\section{Figure 2}

Consumer price index, food price inflation (year on year), 2000-12

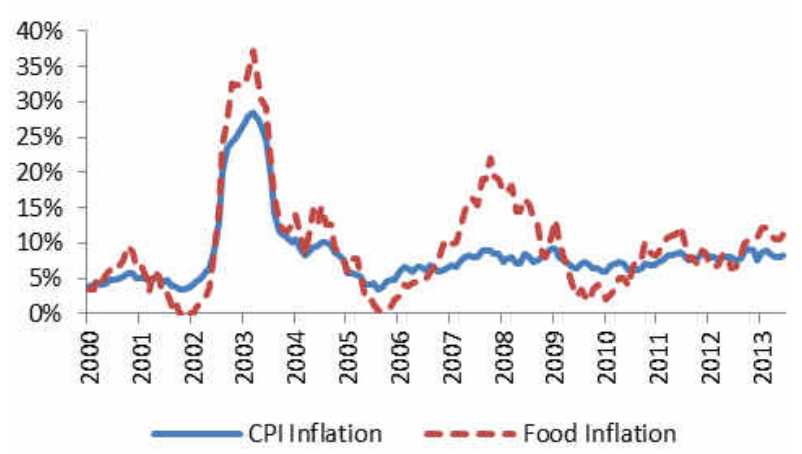

Source: National Institute of Statistics.

Commerce, tourism, and transport were the most rapidly growing sectors in the 10 -year period, while the share of the primary sector declined (figure 3). However, during the Argentine crisis, commerce, tourism, and transport were also the sectors that grew the least (figure 4). The primary sector, on the other hand was more vulnerable to adverse climatic conditions and commodity price shocks. On the demand side, private consumption continued to be the main driver of the economy. 
Figure 3

Sectoral shares of real GDP, 2000-12

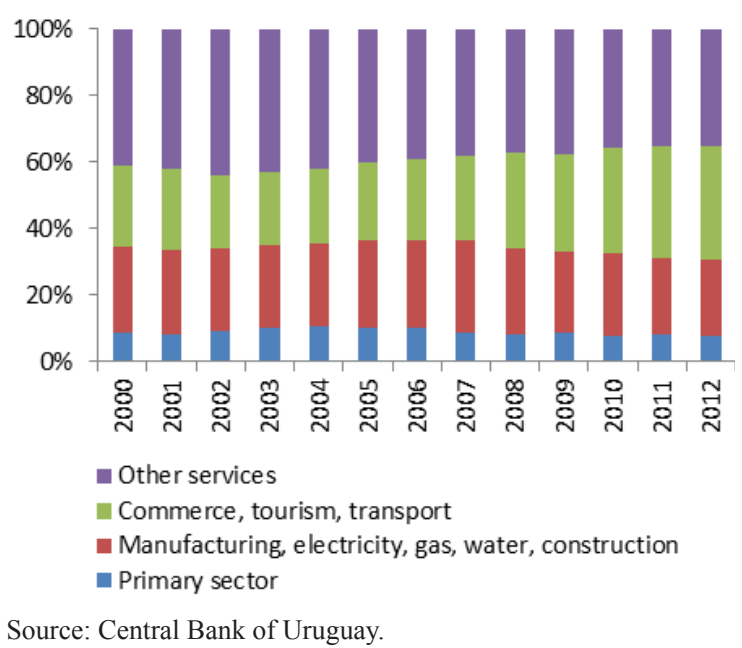

Figure 4

Real sectoral growth rates, 2001-12

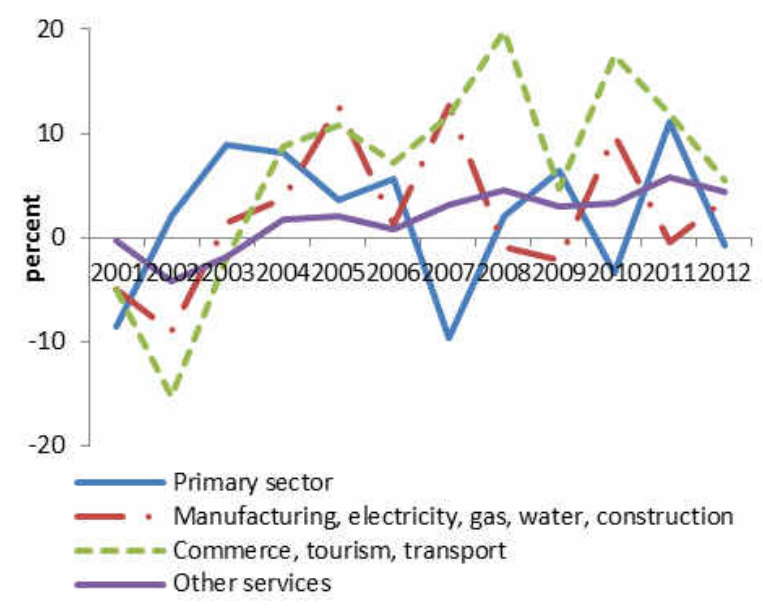

Source: Central Bank of Uruguay.

However, despite these positive developments, significant risks remain. The economy is vulnerable to shocks related to Uruguay's trade dependence on Argentina and Brazil. While Uruguay has diversified its export markets and reduced export concentration, merchandise exports continue to be concentrated in primary products, and the five main trading partners account for 50 percent of total merchandise exports. Brazil is still the country's main trading partner, with 19.9 percent of total merchandise exports in 2012, while Argentina is in fourth place, with 5.7 percent of total merchandise exports. A hard landing in Argentina and slower growth in Brazil could have a significant negative impact on Uruguay's economy.

A possible worsening of the euro area crisis and a prolonged economic downturn in developed countries would likely have negative effects on Uruguay. A potential global economic slowdown would affect Uruguay through channels similar to the channels that were important during the 2008-09 crisis, namely, lower external demand and a drop in commodity prices; lower FDI inflows and heightened risk aversion among investors, leading to a reduction in short-term private portfolio inflows; a loss of access to global financial markets, leading to difficulties in securing financing and increased liquidity risks; and lower fiscal revenues because of reduced economic activity and higher expenditure arising from countercyclical stimulus. An analysis carried out in 2012 estimated that real growth in Uruguay would fall by about 1.7 percentage points under a mild crisis scenario and by almost 5 percentage points in the case of a global recession (World Bank 2012).

In addition, inflationary pressures continue to be a recurring problem for the economy. Although prices were successfully stabilized in the 1990s, strong inflationary pressures, including rising international commodity prices and strong internal demand and supply restrictions on certain goods, led to an increase in average inflation in the consumer price index (CPI) from 4.7 percent in 2005 , the lowest inflation rate after the crisis, to 8.1 percent in 2012, considerably over the target range set by the monetary authority ( 4 to 6 percent). Since the beginning of 2011, the Central Bank therefore repeatedly increased the monetary policy rate, which reached 9.3 percent in December 2012, to curb inflation and to help realign inflation expectations with the official inflation target range.

\subsection{Poverty, shared prosperity, the labor market, and demographics}

The economic crisis of the early 2000s had a negative impact on the welfare of the population that lasted several years. Uruguay had traditionally been among the countries of the Latin America and Caribbean region with the lowest incidence of poverty and inequality, but the effects of the 
crisis significantly and negatively affected most social indicators, including poverty, inequality, unemployment, labor informality, and economic mobility (Gasparini et al. 2011; Lopez-Calva and Lustig 2010). ${ }^{5}$ Moderate poverty almost doubled in one year - from 18.8 percent in 2001 to 35.2 percent in 2002 - and reached 40.0 percent of the population in 2004 (figure 5). At the same time, the size of the middle class shrank from over half of the population to less than three-fifths (World Bank 2013). Most of these indicators began to recover only after 2004, once the economic recovery was well under way and new social policies had been implemented. ${ }^{6}$

Figure 5

Poverty developments, $2000-12$

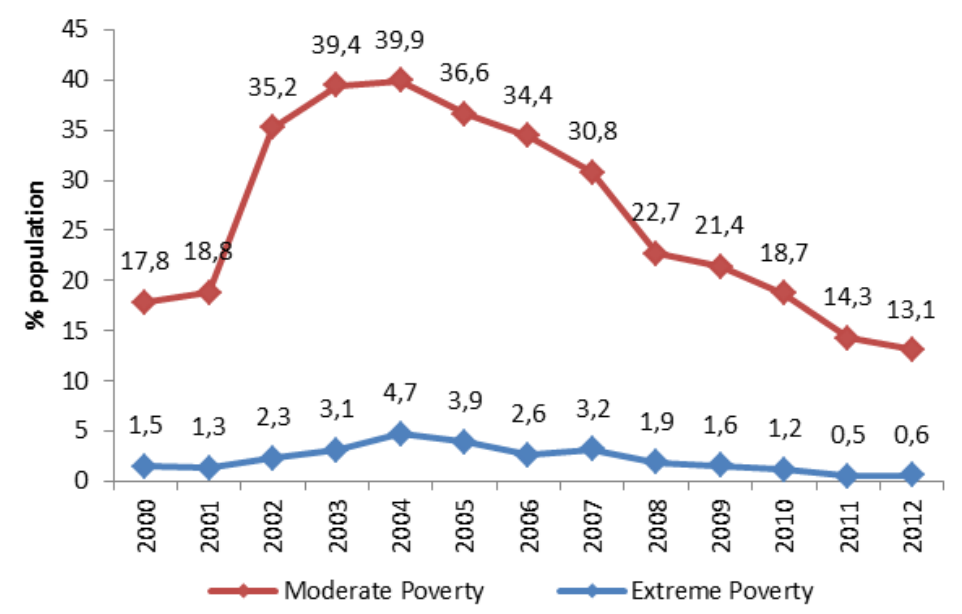

Note: For comparability across time, all numbers are representative of urban areas (more than 5,000 inhabitants) because the Encuesta Continua de Hogares (continuous household survey, ECH) became representative at the national level only after 2006.

Source: National Institute of Statistics.

The incidence of poverty and extreme poverty showed a rapid growth trend in the early $2000 \mathrm{~s}$ and a decline that started after 2004 (see figure 5). The upward trend in poverty rates observed in the early 2000s reversed between 2004 and 2005, at a slow pace at first and, in recent years, more rapidly. By 2012, only 12.4 percent of the population was living with a per capita income below the poverty line, about one-third of the rate seven years earlier. The reduction in extreme poverty was even more dramatic in relative terms: the rate dropped to around 0.5 percent, less than onesixth of the rate seven years earlier.

The observed poverty reduction after 2003-04 was accompanied by strong income growth among the bottom 40 percent of the income distribution in the population (the bottom 40), the World Bank's indicator of shared prosperity. Between 2003 and 2011, using the official income aggregate, we find that the real per capita income of the bottom 40 grew by more than 7 percent annually, while mean income growth was less than 6 percent. In particular, during the first part of the 2002-12 period, 2003 to 2008, real income per capita of the bottom 40 grew at an annualized rate of 7.0 percent, while the mean income growth rate was about 6.1 percent. During the second half of the period, from 2008 to 2011, the less well off in Uruguay benefited more from growth than the average person by even more: the real income per capita of the bottom 40 grew at 7.7 percent, while the mean growth rate was about 5.1 percent. This trend coincides with the expansion of safety nets during the second part of the period.

The labor market trends have been similar to the poverty trends because labor income is the main component of household income. Unemployment expanded during most of the 1990s, reaching a maximum of 16.9 percent of the labor force in 2002 (figures 6 and 7). This problem

\footnotetext{
5 Estimates of poverty in Latin America based on data in SEDLAC (Socio-Economic Database for Latin America and the Caribbean), Center for Distributive, Labor, and Social Studies, Universidad Nacional de La Plata, La Plata, Argentina and World Bank, Washington, DC, http://sedlac. econo.unlp.edu.ar/eng/statistics.php.

6 See annex A for more detail on the data and sources of information.
} 
was compounded by the fact that, among those who managed to retain employment during the crisis, labor informality - defined as jobs with no social security protection - also increased, from slightly below 40 percent in the early 1990 s to a maximum of 42.7 percent in 2004 . The situation began to improve significantly only after 2004. Unemployment fell rapidly and averaged 6.1 percent in 2012, slightly higher than the rate in 2011 (6.0 percent), while informality also declined as a consequence of better macroeconomic conditions and the enhanced enforcement of social security collections.

\section{Figure 6}

Unemployment rates, 2006-12

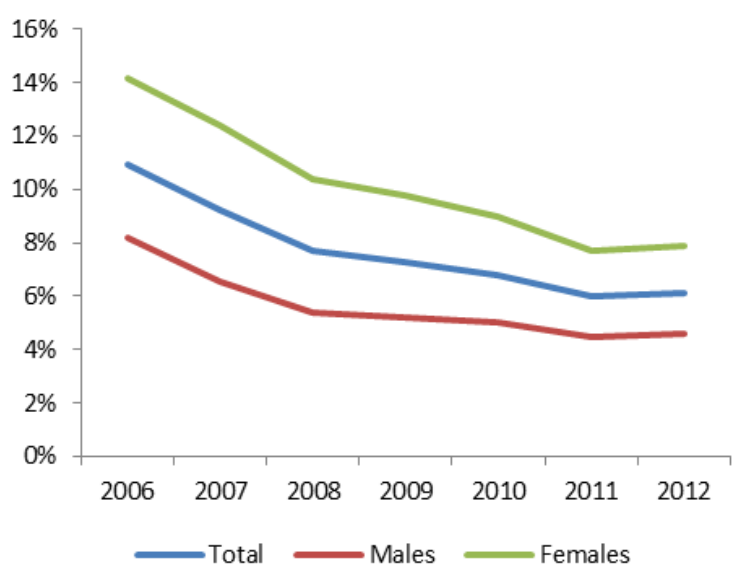

Source: National Institute of Statistics.

\section{Figure 7}

Sectoral employment shares, 2006-12

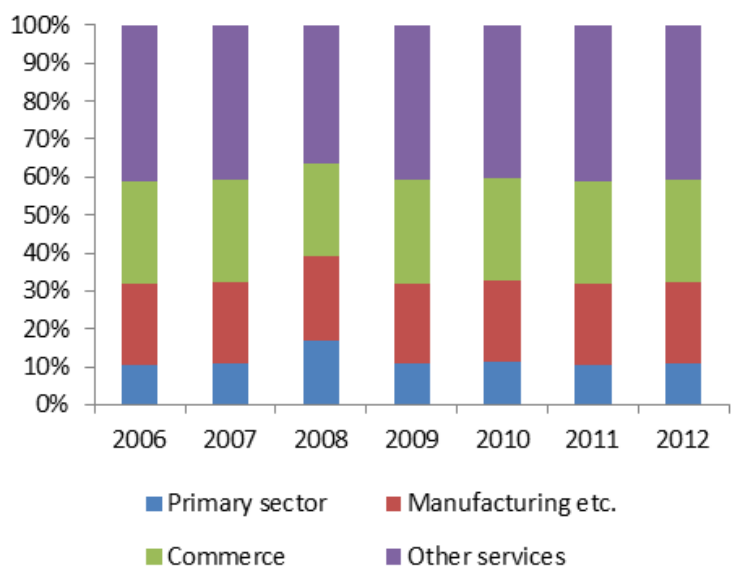

Source: National Institute of Statistics.

Despite the significant progress in poverty reduction, shared prosperity, and upward economic mobility in recent years, a sizable segment of the population is still at risk of falling into poverty or dropping out of the middle class. Estimates of income mobility between 2004 and 2011 suggest that the majority of the people who exited poverty were near the poverty line in 2004 and found themselves only slightly above the poverty line in 2011 , with a median income around $\$ 5$ a day in purchasing power parity U. S. dollars (PPP) (World Bank 2013). Few of the affected households crossed the middle-class threshold. Similarly, most of the people who did enter the middle class in this period were already near the middle-class threshold in 2004. Having entered the middle class by 2011, they had a median income close to $\$ 13$ a day PPP, barely over the middle-class threshold.

Most of the households that exited poverty in Uruguay in recent years have experienced only a modest improvement in welfare that has not allowed them to move into the middle class, and they continue to face a high risk of falling back into poverty. Thus, an additional challenge for the government is to identify this segment of the population and adequately protect it against potential negative shocks.

In our simulation, welfare changes are influenced mostly through the labor market and remittances. Even though labor income is the main component of total income, accounting for 52 percent, other income and other transfers account for 42 percent of total household income (figure 8). These two components, which include pensions and health insurance payments, are of particular importance in the simulations because they are government transfers that are a stable source of income and that are kept constant during the simulation of an economic crisis. The ability of the model to predict household welfare changes is therefore limited to the channel of the labor market and remittances. Along these lines, the results of the model can be seen as a bound that the government can augment by taking action using the automatic stabilizers such as unemployment insurance and increasing social safety nets during the time of crisis. 
Figure 8

Average income composition, 2011

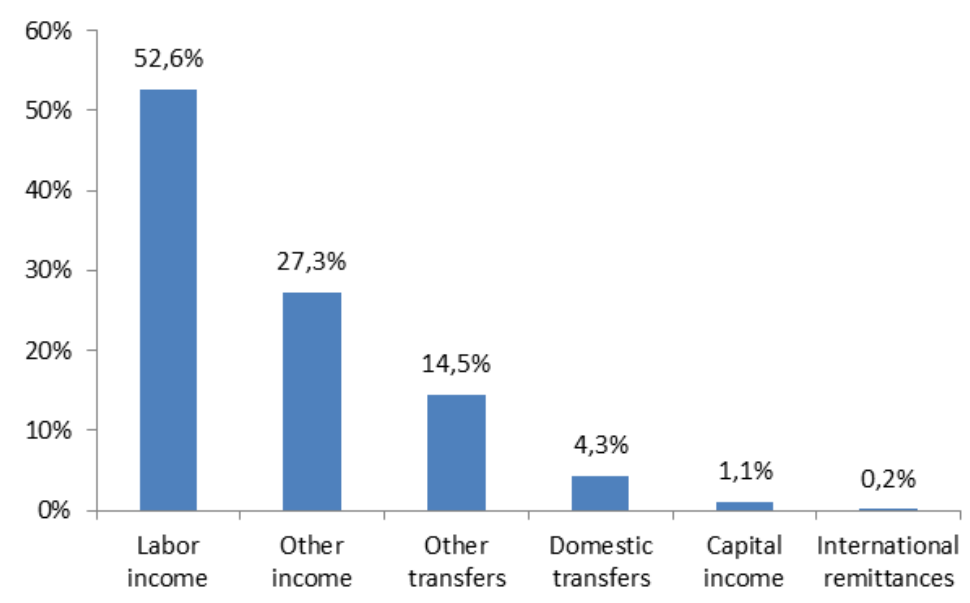

Note: The figure reflects a sample representative at the national level, including Montevideo and urban and rural areas of the interior region Source: World Bank calculations based on ECH 2011.

The demographic structure of Uruguay has changed significantly in the past decade, and Uruguay's aging process is the most advanced in the region. Uruguay's population in 2010 has been estimated at 3.4 million. A comparison between 2000 and 2010 shows that the demographic pyramid has narrowed in the infant population segment (under age 10) and widened significantly in the population segment corresponding to age 30 and up (figure 9). Uruguay's population is aging, and the middle population segment represents a large share. Uruguay has the oldest population in the region, followed by Argentina and Chile (Cotlear 2011). Uruguay also has a low fertility rate, which, at 2.1 children pre woman, is only at the replacement rate.

Figure 9

Demographic structure, Uruguay, 2000 and 2010
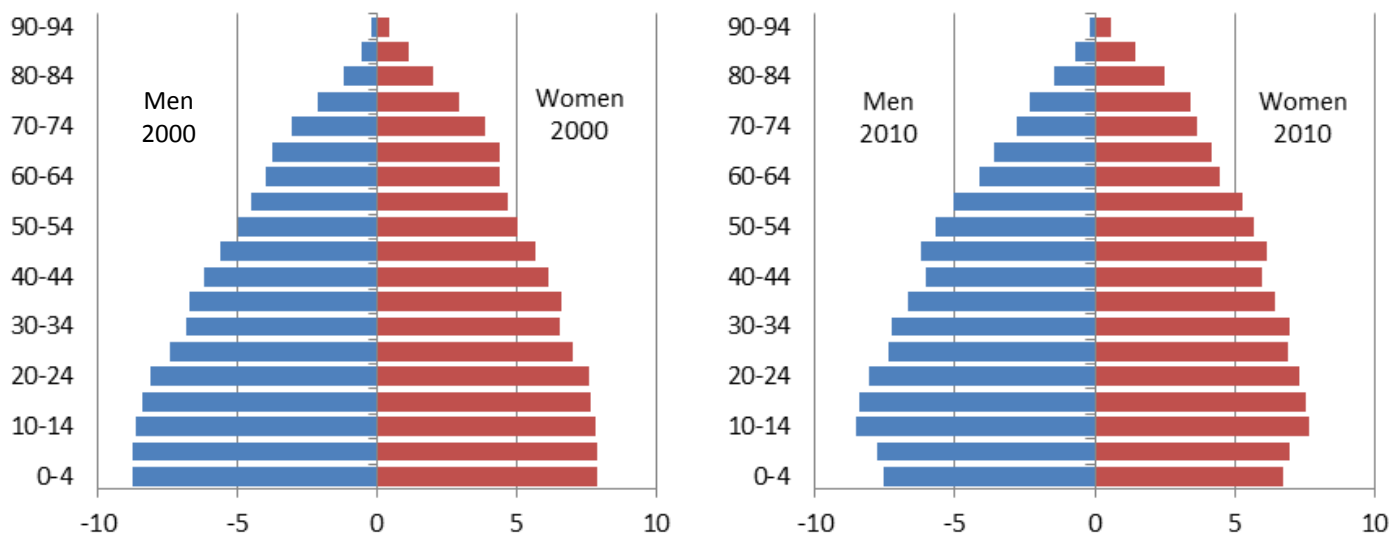

Source: National Institute of Statistics.

\section{MACROECONOMIC PROJECTIONS}

Two main scenarios are considered for this analysis. While the benchmark (no-crisis) scenario assumes business as usual, without major disruptions to economic development, the crisis scenario simulates a situation similar to the one during the Argentine crisis in 2001-02. Projections for the benchmark (no-crisis) scenario are formulated based on forecasts of the Ministry of Economy and Finance, local consultancy companies, and internal World Bank models. The crisis scenario is mainly based on developments during the crisis a decade ago and assumes that external shocks 
hit the economy, leading to negative real growth and double-digit inflation. GDP as well as employment shares are divided into the following four sectors: (1) the primary sector, including agriculture, fishing, and mining; (2) manufacturing, including gas, water, electricity, and construction; (3) commerce, tourism, and transport; and (4) other services, including financial and real estate services, public administration, health care, and education. In addition, an alternative crisis scenario has been formulated that assumes conditions similar to those during the 2008-09 crisis, which is presented briefly in section 5. The scenarios are developed for two consecutive years, which will be identified as year 1 and year 2 in the remainder of the paper.

\subsection{GDP, inflation, and remittances}

Growth is expected to be moderate over the medium term in both scenarios (table 1). Sustained, but lower growth is projected because of the more challenging international economic environment and the expected return to the estimated potential growth rate. Internal demand is projected to remain the key driver of economic growth, mainly explained by private consumption. Investment is expected to remain strong, supported by large FDI inflows. As in previous years, net exports are projected to contribute negatively to growth, especially during year 1. CPI inflation is expected to start declining in year 1, mainly because of the projected deceleration of economic activity, and to approach the monetary authority's target range of 4 to 6 percent gradually thereafter.

Table 1

Projections of the GDP growth rate and inflation under the benchmark (no-crisis) and crisis scenarios, year 1-year 2 (percent)

\begin{tabular}{|c|c|c|c|c|c|c|c|c|c|}
\hline & \multicolumn{3}{|c|}{ GDP } & \multicolumn{3}{|c|}{ CPI } & \multicolumn{3}{|c|}{ Food CPI } \\
\hline & Benchmark & Crisis & Difference & Benchmark & Crisis & Difference & Benchmark & Crisis & Difference \\
\hline 2011 & 6.5 & 6.5 & - & 8.1 & 8.1 & - & 9.6 & 9.6 & - \\
\hline $\begin{array}{l}\text { baseline } \\
\text { year } \\
(2012)\end{array}$ & 3.9 & 3.9 & - & 8.1 & 8.1 & - & 8.4 & 8.4 & - \\
\hline year 1 & 4.0 & -7.7 & -11.7 & 7.1 & 13.9 & 6.8 & 6.5 & 7.0 & 0.5 \\
\hline year 2 & 4.0 & 0.8 & -3.2 & 6.1 & 9.2 & 3.1 & 6.4 & 6.7 & 0.3 \\
\hline
\end{tabular}

Note: GDP = GDP at factor cost. 2011 and 2012 are actual data.

Sources: Central Bank of Uruguay, National Institute of Statistics, and World Bank calculations.

Under the benchmark scenario, therefore, a real GDP growth rate of 4.0 percent is assumed in years 1 and 2, close to the estimated potential GDP growth. Commerce, tourism, and transport are expected to follow a similar trend as in past years, although somewhat more slowly, and to expand at the most rapid rate among sectors, while the primary sector is expected to experience slower growth rates. In line with a slowdown in the economy, overall inflation is expected to decline to 7.1 percent in year 1 and to 6.1 percent in year 2. Food inflation will similarly decline to 6.5 percent in year 1 and 6.4 percent in year 2 .

Under a more pessimistic crisis scenario, however, a recession similar to that experienced in 2001-02 is assumed, with a contraction of real GDP by 7.7 percent in year 1, followed by a more rapid recovery than the one after the Argentine crisis, with an increase in real GDP of 0.8 percent in year 2 . A particularly sharp decline is assumed in manufacturing and in commerce, tourism, and transport, which are more immediately affected by the downturn. Overall inflation 
is projected to follow a trend similar to the trend in 2001-02 as well, peaking at 13.9 percent in year 1 and declining to 9.2 percent in year 2 .

Remittances have not played an important role in the Uruguayan economy so far. Compared with other Latin American countries, remittances have not been a major contributor to the Uruguayan economy, representing less than 1 percent of GDP, reaching about \$120 million in 2012. Similar trajectories have therefore been assumed in remittances in year 1 and year 2, following the past trend, with slightly lower values in the crisis scenario.

\subsection{Population and the labor market}

Uruguay's population is not expected to change substantially during year 1 and year 2 . Projections have been obtained from the National Institute of Statistics and reflect an increase of only 1.4 percent, or 38,000 people, between the baseline year (2012) and year 2 .

The adjustment of the labor market to past output changes is used to project future adjustments. To assess the household-level adjustment to changes in the labor market on the macroeconomic level, we assume that changes in labor market conditions are proportional to changes in output, based on the estimated past relationship between output and employment and requiring the specification of sectoral and total output-employment elasticities. The elasticities are calculated using the past GDP and employment changes in each sector as the percentage change in employment in the sector between years $t-1$ and $t$ in response to a 1 percent change in sector output in the same period. The calculated parameters fluctuated quite substantially over the last five years of the period, especially during the 2008-09 crisis, leading to the omission of 2008 and 2009 in the calculation under the no-crisis scenario, but they settled down more appreciably in 2010-11.

Employment shares are not expected to change drastically. Under the benchmark scenario, sectoral employment shares will stay basically unchanged, with a small shift from manufacturing to commerce, tourism, and transport, which are anticipated to grow at the most rapid rate. In the crisis scenario, based on the assumed output response in the respective sectors, the decline in the employment shares of commerce, tourism, and transport as well as in other services will be more pronounced.

\subsection{The interaction of microdata and macrodata}

One of the key assumptions of the simulation is that microeconomic variables do not change their behavior in an economic crisis and that the growth rates of labor income and profits are the same as the aggregate product rates in each sector (see section 2). To validate the assumption that microeconomic data follow macroeconomic fundamentals, figure 10 shows the real growth rates of GPD per capita and the per capita official mean income based on the available household surveys. As can be seen, mean income per capita generally follows GDP per capita. However, the movements of mean per capita income tend to lag and overreact relative to the movements in GDP per capita. This behavior does not violate the assumptions needed for the correct implementation of the model, but show that the reactions to a macroeconomic shock become evident one period later than expected. 
Figure 10

Historical comparison: growth rates of macro and micro mean income

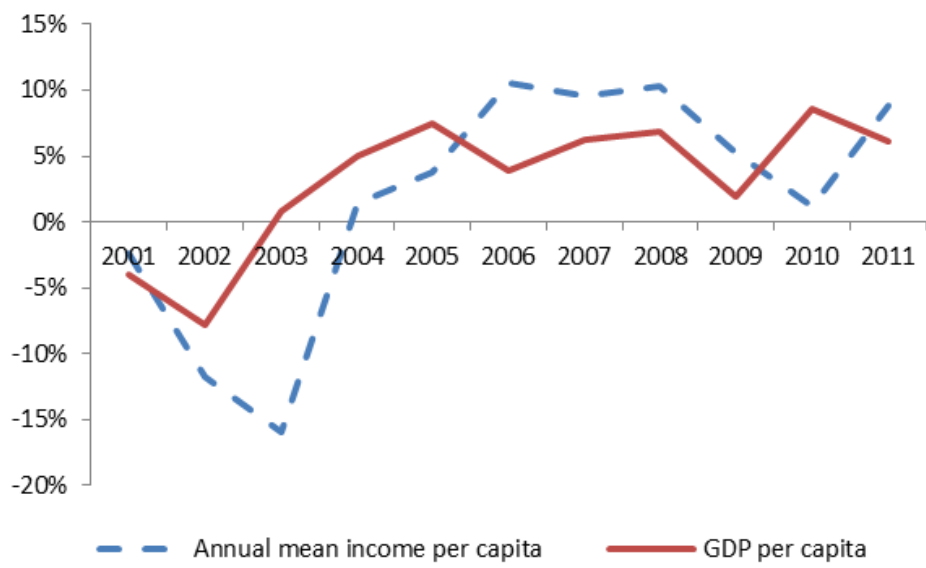

Note: For comparability across time, all numbers in the figure are representative of urban areas (more than 5,000 inhabitants) because the ECH became representative at the national level only after 2006.

Source: World Bank calculations based on data of the Central Bank of Uruguay and the ECH.

\section{SIMULATION RESULTS}

We constructed two microsimulations for each year to compare the results on poverty, shared prosperity, and the overall income distribution between the benchmark (no-crisis) and crisis scenarios. The simulation parameters and the results of the simulation are presented in the following subsections.

\subsection{Simulation parameters}

The simulations are based on a comparison of the benchmark scenario and the crisis scenario. The scenarios developed for the baseline year (2012), year 1, and year 2 were then mapped to the 2011 Encuesta Continua de Hogares (continuous household survey, ECH) released by the National Institute of Statistics. The macroeconomic parameters used in the simulations are presented in figure 11. They represent the percentage change in each indicator relative to the level in 2011. Annualized real GDP growth is 4.1 percent higher in year 1, under the benchmark scenario, than in 2011, whereas, under the crisis scenario, it is 2.0 percent lower. Moreover, different sectoral growth rates are simulated in each of the scenarios, which explain the dissimilarities in the unemployment rates. In year 2, under the crisis scenario, GPD is expected to contract by 1.0 percent (annualized growth rate) with respect to the 2011 level, while, under the no-crisis scenario, real GDP would be 4.0 percent higher, in annual terms, than it was in 2011. 
Figure 11

Benchmark (no-crisis) and crisis projections: annualized GDP growth relative to 2011

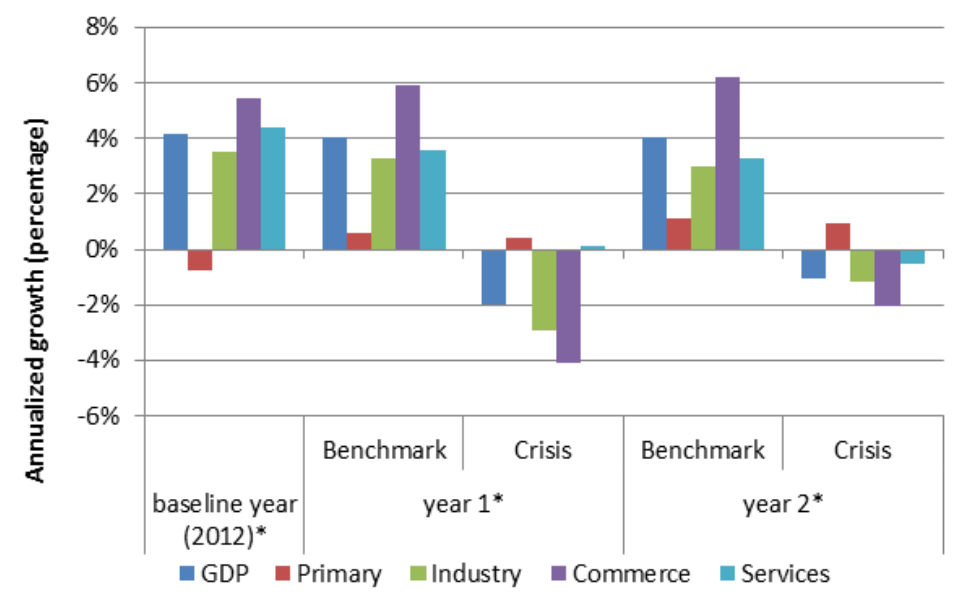

* Change with respect to 2011 .

Source: World Bank calculations based on data of the Central Bank of Uruguay and the ECH 2011.

Under the crisis scenario, similar to the 2001-02 crisis, all sectors except the primary sector are expected to be affected negatively (figure 12). The resulting annualized unemployment rate would be 13.4 percent higher than the rate in 2011 mainly because of the contraction in industry and commerce, which, in 2011, accounted for 21 and 27 percent of the employed population, respectively. ${ }^{7}$ In the absence of a crisis, activity, employment, and unemployment rates are not expected to change significantly in year 1 , but, by year 2 , the unemployment rate is predicted to decrease at an annual rate of over 1 percent.

\section{Figure 12}

Benchmark and crisis projection: annualized labor growth relative to 2011

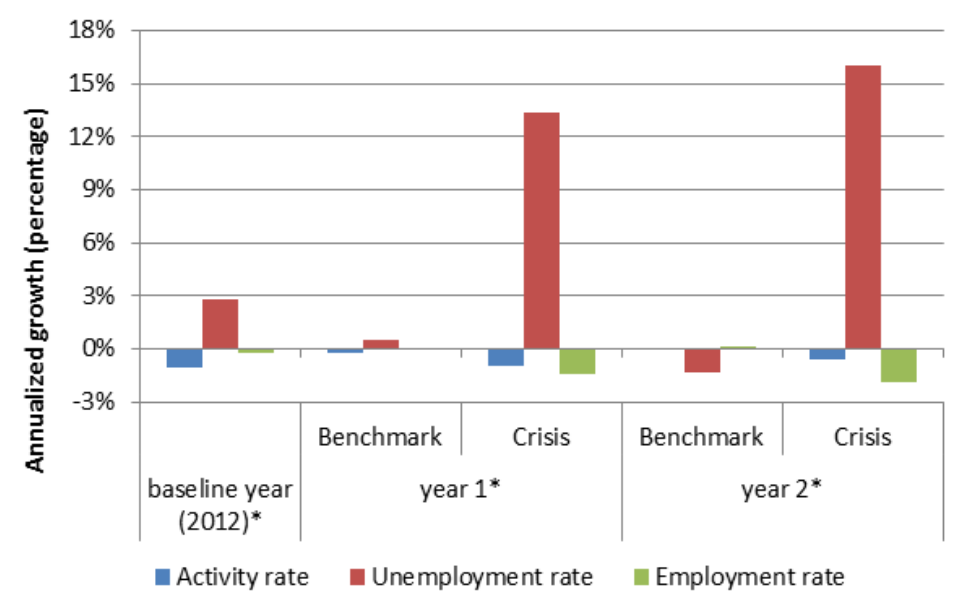

* Change with respect to 2011 .

Source: World Bank calculations based on data of the Central Bank of Uruguay and the ECH 2011.

Calculations based on the $2011 \mathrm{ECH}$. 


\subsection{The impact on poverty, inequality, and shared prosperity}

Figure 13 presents the results of the microsimulations on poverty and inequality. Chart a, figure 13 shows the levels of moderate poverty among individuals and households and the poverty gap (Foster-Greer-Thorbecke [1984] FGT $_{1}$ ), while chart b, figure 13 shows the Gini and Theil coefficients.

\section{Figure 13}

The impact of a crisis on poverty and inequality

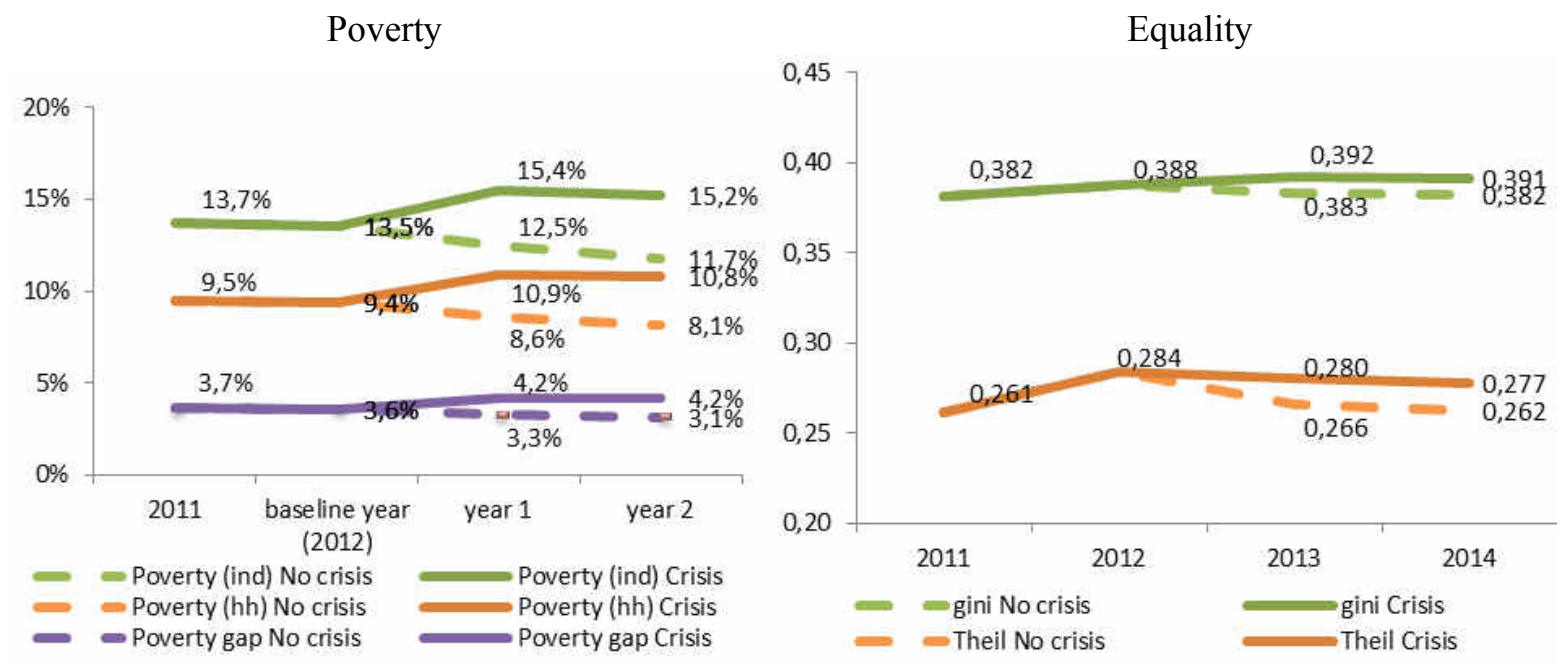

Source: World Bank calculations based on data of the ECH 2011.

As expected, the level and depth of poverty are greater in the crisis scenario (figure 13). In the benchmark scenario, poverty declines from 13.7 percent in 2011 to 11.7 percent in year 2 . However, if a crisis were to strike, poverty is predicted to increase to 15.4 percent and 15.2 percent in year 1 and year 2, respectively. This represents an average poverty rate that is 3.5 percentage points higher than it would have been in the absence of the simulated macroeconomic shocks and 1.5 percent higher than the poverty levels in 2011. An important results is that, under the crisis scenario, not only more people are living under the poverty line, but the depth of poverty, measured by $\mathrm{FGT}_{1}$, increases as well, implying that more resources would be needed to assist the poor.

The impact on poverty, however, would be less severe under the crisis scenario than during the 2001-02 Argentine crisis. It is worth putting the results of the predictions in context. While any increase in the share of the poor in the population warrants attention, it is equally important to contrast the expected 3.5 percent rise with the 20 percent spike observed after the 2001-02 Argentine crisis. There are certainly various factors that might explain these results, notably the increasing role of social transfers and other nonlabor incomes in household incomes relative to the beginning of the decade.

In past years, the noncontributory components of the Uruguayan social protection system were expanded considerably. The implementation of the Plan de Atención a la Emergencia Social (the National Social Emergency Response Plan, PANES, 2005-07), replaced by the Tarjeta Uruguay Social (a means-tested food voucher, 2006) and the Asignaciones Familiares - Plan de Equidad (a noncontributory family allowance, 2008), extended social benefits to the lowest-income population. The implementation of new social programs is reflected in the expanding share of transfers in total income. ${ }^{8}$ In particular, transfers represented 3 percent of total household income

8 The transfers encompass government transfers other than noncontributory pensions. Specifically, the programs included are unemployment insurance, hogar consituido, and the family allowance, Asignaciones Familiares. 
in 2003, while, in 2011, they represented almost 10 percent (figure 14, chart a). ${ }^{9}$ Additionally, the coverage of public transfers also expanded, from 26 percent of households in the first quintile in 2003 to 70 percent in 2011 (figure 14, chart b). ${ }^{10}$

Rofman (2013) also shows that social transfers are an important part of income among households in the first decile of the income distribution and estimates that noncontributory transfers led to a reduction of 10 percent in poverty incidence, 16 percent in poverty intensity, and 23 percent in poverty severity. He also analyzes the vulnerability of households and shows that the combination of a rise in unemployment to 2002 levels and a 10 percent reduction in real household income would increase the poverty rate to 26.8 percent if the current transfers system remains in place and to 32.2 percent if the prevailing system were that of 2002 , thereby highlighting the importance of social transfers.

\section{Figure 14}

Trends in public transfers, 2003 and 2011

a. Public transfers, share of total income

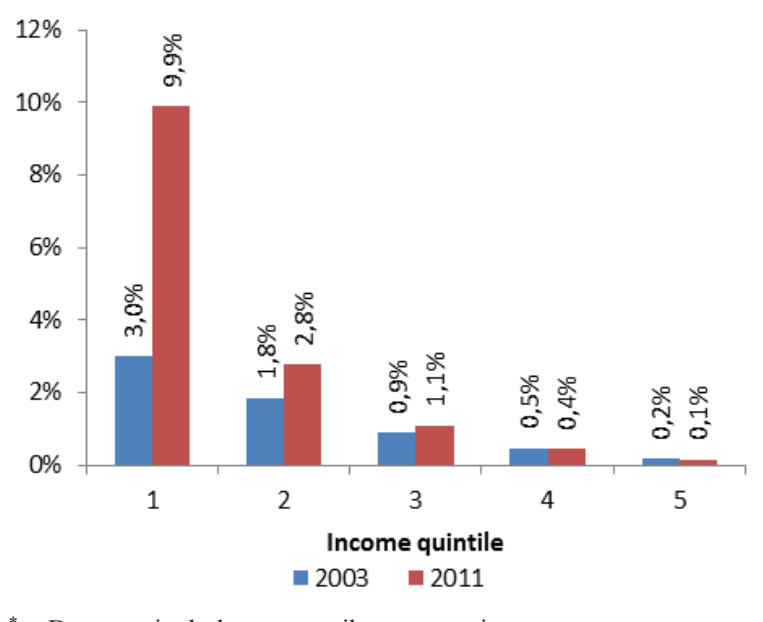

b. Households receiving public transfers, $\%{ }^{*}$

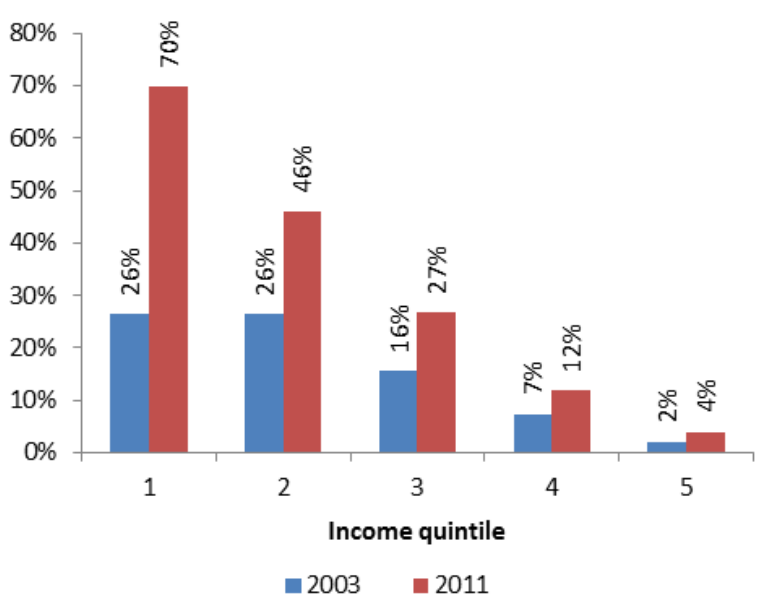

Does not include noncontributory pensions

Note: To facilitate comparability across time, all data in the figure are representative of urban areas (more than 5,000 inhabitants) because the ECH became representative at the national level only after 2006.

Source: World Bank calculations based on data of the 2003 and $2011 \mathrm{ECH}$.

The change in poverty can be understood more accurately by analyzing the impact on the labor market and on the sources of incomes. Even though the unemployment rate tends to remain around 6 percent in the benchmark scenario, and there are no important changes in the share of the inactive population, the unemployment rate is 1.4 percent higher in year 1 and 3.3 percent higher in year 2 under the crisis scenario relative to the no-crisis scenario. As a consequence, the average household income in year 1 and year 2 in the crisis scenario is 6.4 percent and 8.1 percent lower relative to the benchmark scenarios (figure 15). Meanwhile, relative to 2011, the average household per capita income in year 1 and year 2 in the absence of a crisis would be 4.3 percent and 6.7 percent higher, respectively.

\footnotetext{
9 In this period, the mean transfer per capita among the first quintile rose from Ur\$44 to Ur\$293 a month (values in 2005 Montevideo prices).

10 In the case of the family allowance, Asignaciones Familiares, administrative data show that its coverage increased 36 percent between 2003 and 2011, from 402,672 to 549,295 beneficiaries (2011 data of the Banco de Previsión Social).
} 
Figure 15

Impact of the crisis on household income: Proportional change in income components relative to 2011

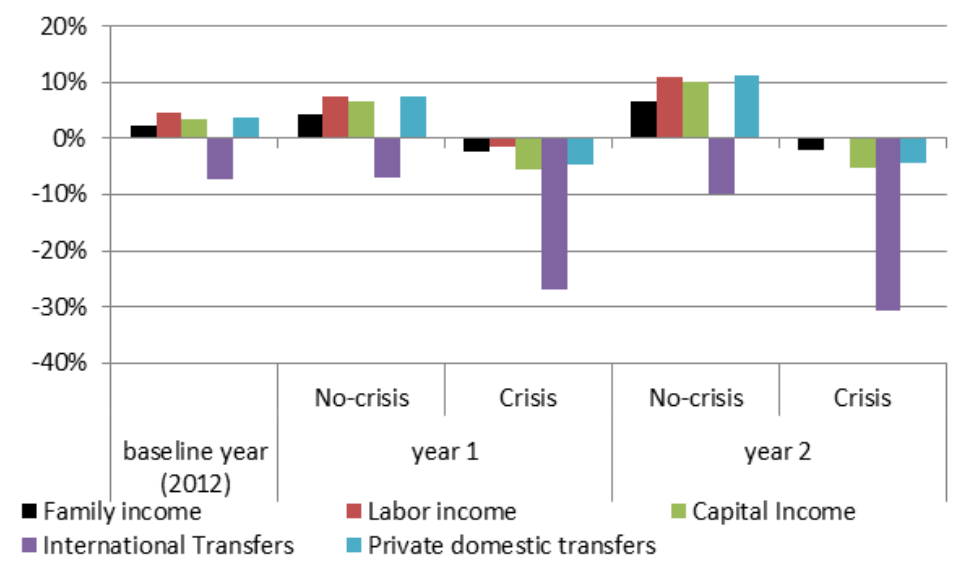

Source: World Bank calculations based on data of the Central Bank of Uruguay and the ECH 2011.

Disaggregating household income into its components, we find, under the crisis scenario, that the largest falls are in capital income, international transfers, and private domestic transfers. Yet, because only a relatively small share of households possess these income sources, the main source of the change in per capita household income is the reduction in labor market income. ${ }^{11}$ In year 2 under the crisis scenario, labor income would be 9.7 percent lower than predicted in the absence of a crisis and 0.1 percent lower relative to mean labor income in 2011. This means that the main effect of the crisis occurs in terms of the labor incomes lost because of the unfavorable macroeconomic shock that would have hit the economy. ${ }^{12}$

In terms of the impact of a crisis on employment by sector, the simulation predicts lower shares of employment in trade and services relative to the absence of crisis. The flipside is that the share of the active population employed by industry is higher in the crisis scenario than in the no-crisis scenario, even though industry would be greatly affected by the crisis in terms of GDP (figure 16). Meanwhile, the primary sector experiences no major changes under the crisis scenario relative to the benchmark scenario.

Figure 16

Sectoral employment shares: the benchmark versus the crisis scenario, $\%$ change

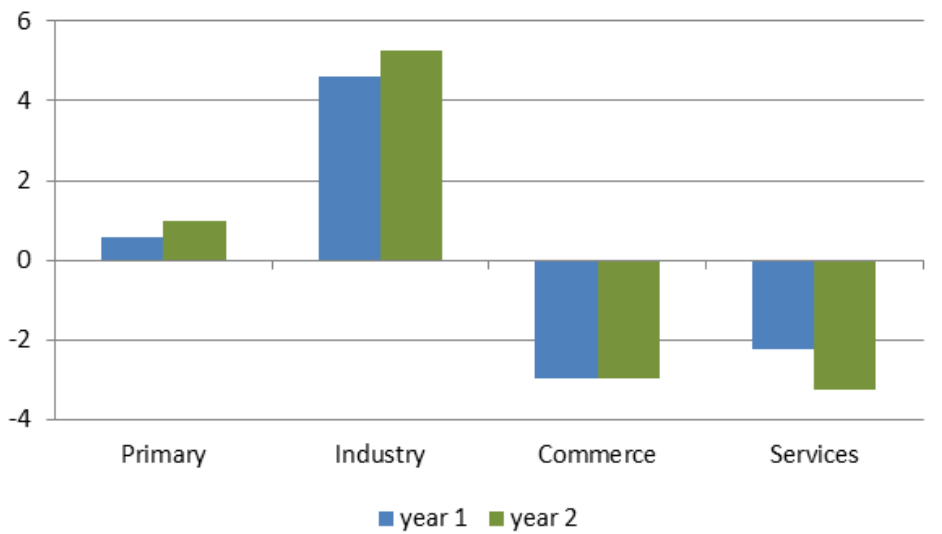

Source: World Bank calculations based on data of the Central Bank and the National Institute of Statistics.

11 According to the $2011 \mathrm{ECH}$, capital transfers are received by 8.4 percent of Uruguayan households; international transfers by 1.8 percent; and private domestic transfers by 26 percent. In the case of public transfers, they represented, on average, 18 percent of household per capita income by 2011 .

12 The model keeps income from social benefits, pensions, and other transfers constant at the preshock level (see section 2). Because these components are important in the total income aggregate in Uruguay, the ability of the model to explain the total income change may be limited. See annex B for further explanations on the validation exercise. 
Relative to the benchmark scenario and the growth rate of mean income, a crisis would significantly reduce income growth among the bottom 40. In particular, the indicator of shared prosperity in Uruguay would decline from 13.3 percent in 2010-11 to 0.8 percent in 2011-12, would become negative between the baseline year and year 1 at -5.6 percent, and would show a slight recovery in year 1-year 2, with a growth rate of 0.7 percent (figure 17). In the baseline year and year 1, income growth among the bottom 40 would be less than the growth of the mean, which may translate into an increase in inequality, while, in year 1-year 2, the two growth rates would be only a little above zero.

\section{Figure 17}

Impact of the crisis on shared prosperity (income growth among the bottom 40)

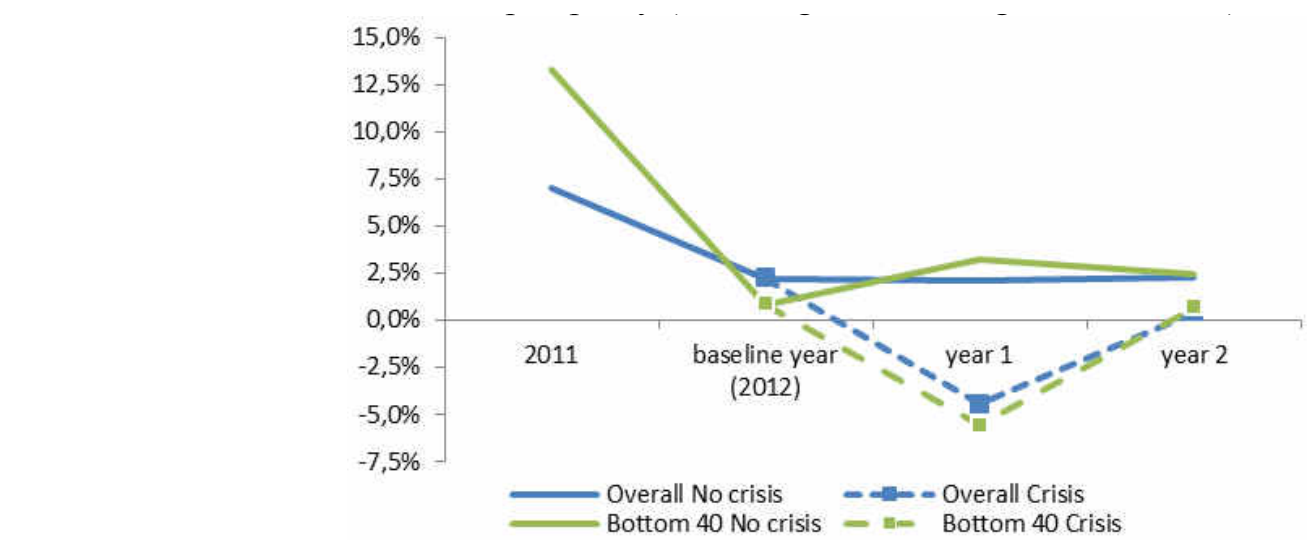

Source: World Bank calculations based on data of the Central Bank of Uruguay and the ECH 2011.

Similar to poverty rates, the impact of a crisis on shared prosperity would be less severe than the impact of the 2001-02 economic shock. In 2001 and 2003, the Argentine crisis produced negative income growth rates among the bottom 40 of -5.2 percent between 2001 and 2002, and of -16.9 percent between 2002 and 2003; while the growth rate in mean income was -3.3 percent and -19.0 percent, respectively. A simulated crisis from the baseline year to year 2 would also have negative consequences on shared prosperity, but not as severe in magnitude as the consequences of the 2001-02 Argentine crisis.

\subsection{Heterogeneous effects of the crisis}

To clarify the distributional implications of a possible crisis, figure 18 shows descriptive statistics on households grouped by the trajectory of poverty under the crisis scenario relative to the no-crisis scenario in year 2. We distinguish three types of households: always poor (living below the poverty line with or without crisis), never poor (living above the poverty line in both scenarios), and vulnerable to crisis (households that would not be considered poor in the absence of crisis, but are expected to be considered poor were the shock to hit Uruguay as simulated). ${ }^{13}$

\footnotetext{
13 There is also a fourth group: households that would be poor in the absence of crisis, but that would be living above the poverty line were the crisis to strike. Because there is a negligible share of individuals in this group, it is ignored for clarity of exposition in figure 18.
} 
Figure 18

The crisis scenario, year 2: household composition, residence, educational level, and other characteristics
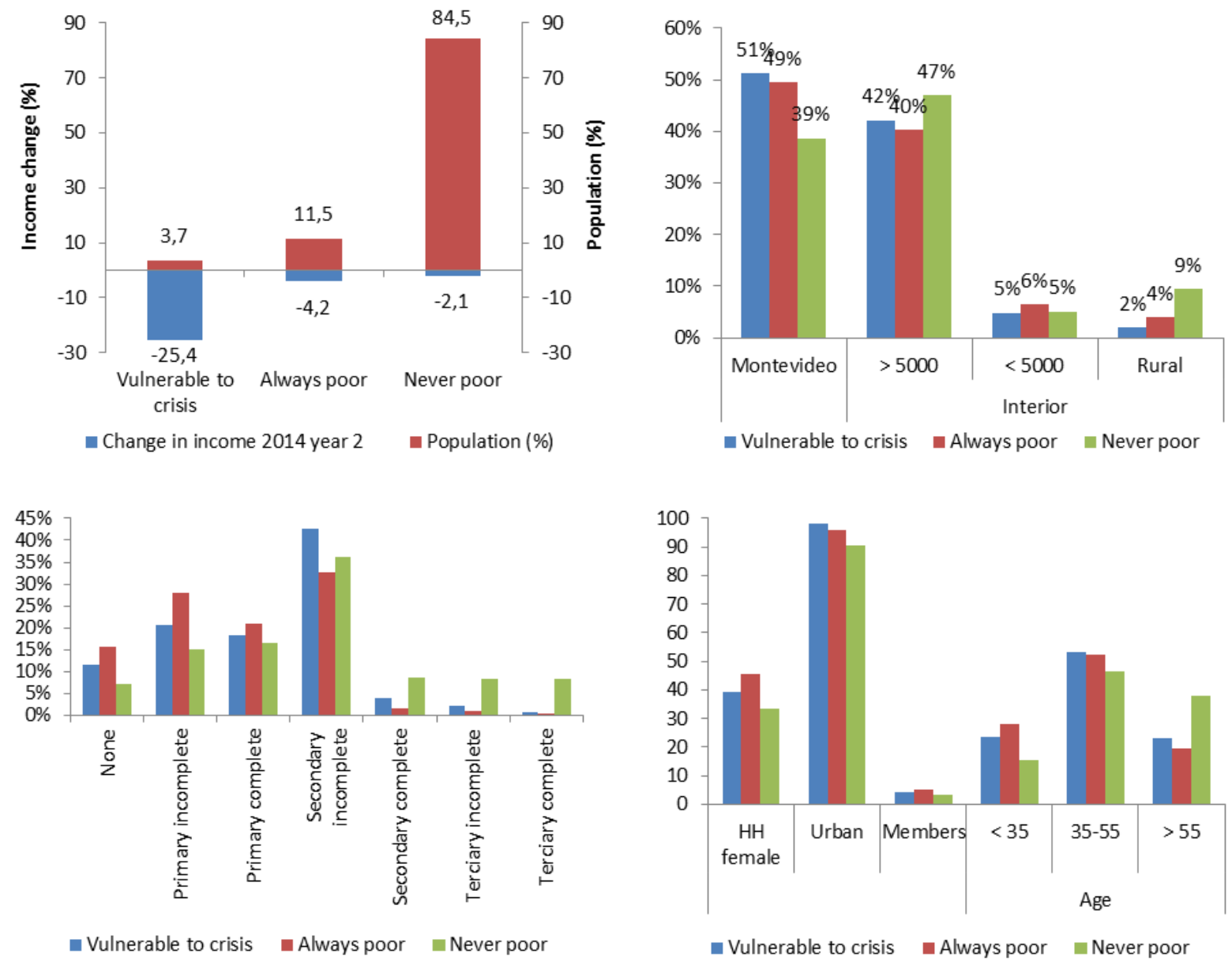

Note: Status is evaluated according to simulations for year 2: Always poor (poor with or without a crisis), never poor (not poor in either scenario), and vulnerable to crisis (poor in the crisis scenario not poor without a crisis).

Source: World Bank calculations based on data of the ECH 2011.

According to the simulation, 3.7 percent of the total population is vulnerable to fall into poverty if there were a crisis. Average per capita household income would be almost 30 percent less among this group in a crisis than in the absence of a crisis. The other groups would also lose income in a crisis, but the magnitude of the income change would be smaller.

Three interesting patterns emerge. First, households that are always poor (that is, poor in year 2 under both scenarios) show a higher incidence of woman-headed households and larger households relative to the rest of the population. The same is true among households that would fall into poverty were a crisis to occur. Second, the share of households that are always poor or vulnerable to crisis in rural areas is smaller than the share of households that are never poor. Third, households that are vulnerable to crisis seem to show not only higher unemployment rates in the crisis scenario than in the no-crisis scenario, but also a higher share of people out of the labor force altogether (figure 19). Relative to the benchmark (no-crisis) scenario, most people who would cease to work (become inactive) are now working in commerce and services. 
Figure 19

Changes in the labor market

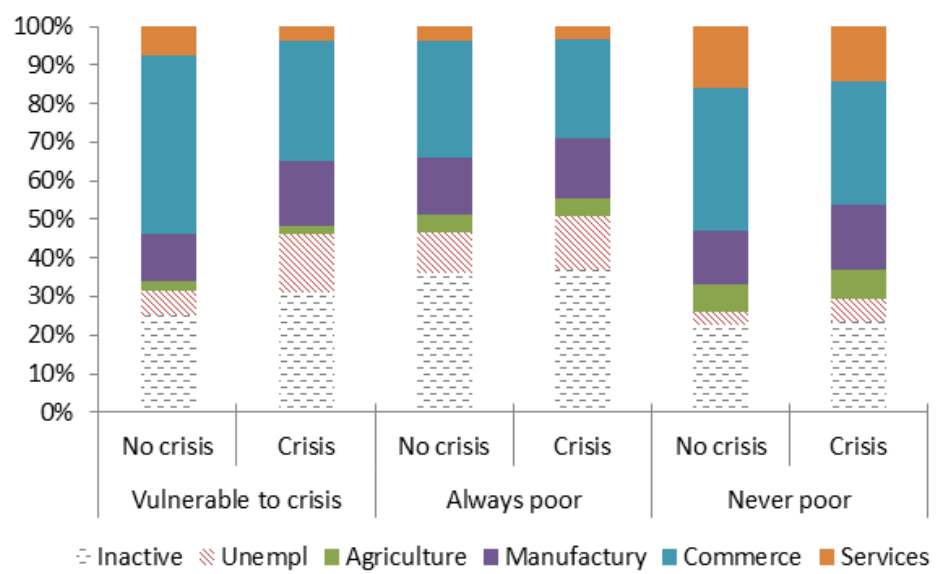

Note: Status is evaluated according to simulations for year 2: Always poor (poor with or without a crisis), never poor (not poor in either scenario), and vulnerable to crisis (poor in the crisis scenario not poor without a crisis).

Source: World Bank calculations based on data of the ECH 2011.

The decline in the growth rate is the main contributor to higher poverty rates in the case of the simulated crisis relative to the absence of the crisis. Following Datt and Ravallion (1992), we may decompose the increments in moderate poverty into increments that arise from changes in the income level (growth) and those that arise from changes in the income distribution (redistribution). Figure 20 presents the decomposition into these two components nationwide and in urban and rural areas and compares the year 2 benchmark (no-crisis) and crisis scenarios. The lack of growth is the main driver of the poverty increments in both urban and rural areas and, thus, at nationwide. However, as the figure shows, taking into account only the effect of negative growth would understate the rise in moderate poverty levels because the widening inequality in the income distribution plays an important role in explaining the predicted increments in poverty rates.

Figure 20

Datt-Ravallion decomposition: benchmark vs. crisis scenario, \% change

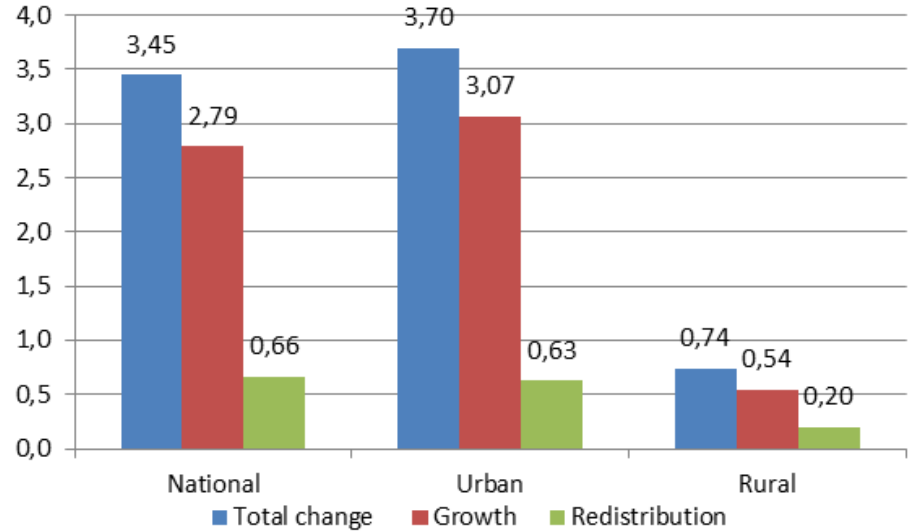

Source: World Bank calculations based on data of the ECH 2011.

The results of the Datt-Ravallion decomposition are consistent with the growth incidence curves (figures 21 and 22). These figures show, for each percentile, the net income change of the year 2 crisis scenario relative to the benchmark scenario. In all three areas (nationwide, urban and rural), the mean growth rate, that is, the average growth rates across percentiles, is negative at between -2 percent and -14 percent. In rural areas, the effect of a crisis would be more evenly distributed across the percentiles of the income distribution. 
Figure 21

Growth incidence curve: benchmark vs. crisis scenario, year 2, nationwide

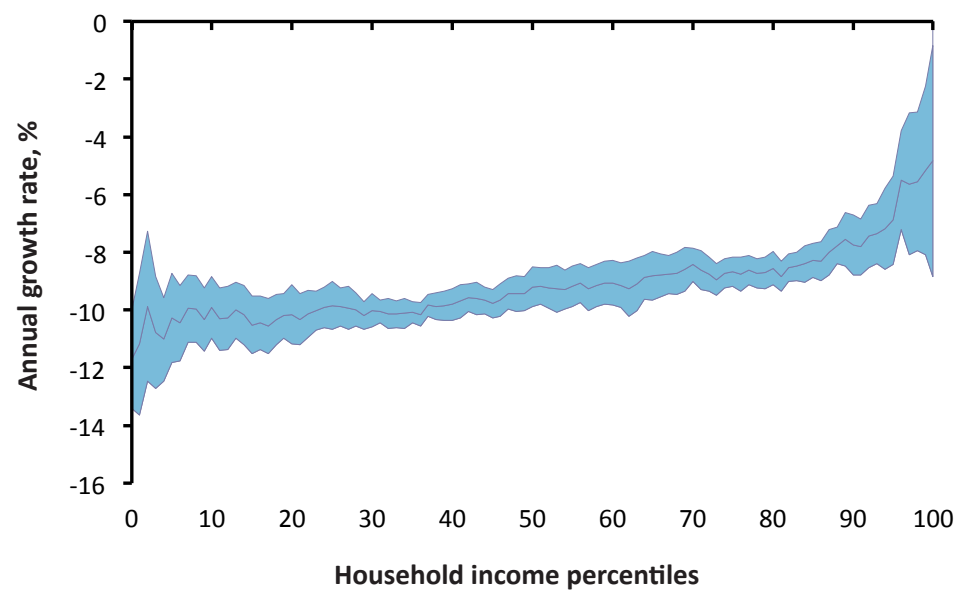

Figure 22

Growth incidence curve: benchmark vs. crisis scenario, year 2

a. Urban

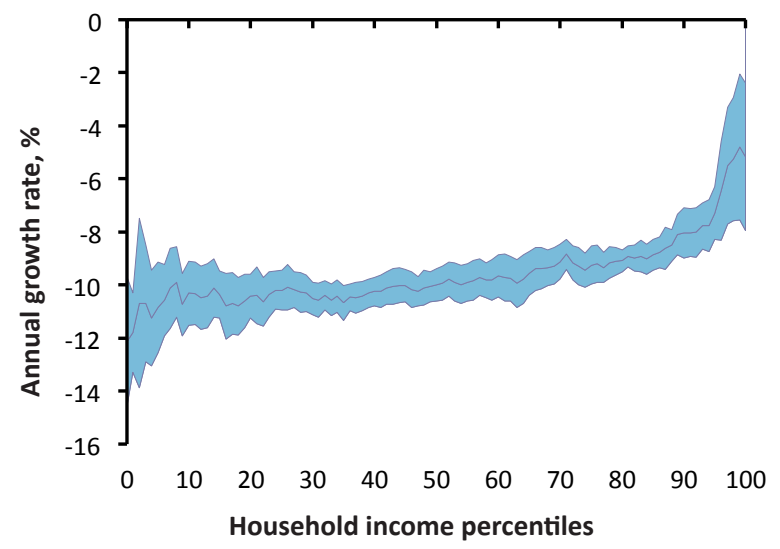

Source: World Bank calculations based on data of the ECH 2011. b. Rural

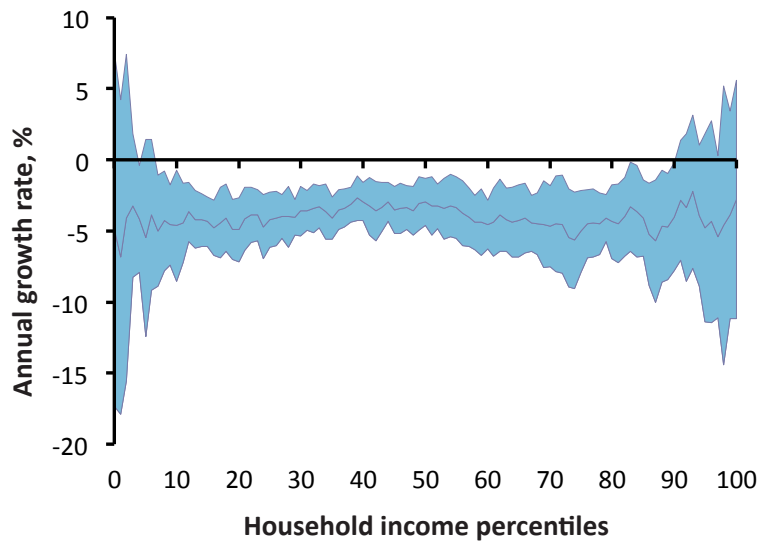

\subsection{Simulation of the $2008-09$ crisis}

In addition to the crisis scenario outlined above, we have formulated an alternative crisis scenario that assumes conditions similar to those in 2008-09. The 2008 financial crisis did not have an effect on the Uruguayan economy similar to the devastating effect of the Argentine crisis of 2001-02; nonetheless, growth declined substantially. The manufacturing sector was affected because of its strong links with the Southern Cone Common Market, particularly Brazil (Estrades and LLambí 2013).

Similarly to the analysis above, we consider two scenarios. The benchmark scenario is the same as the benchmark scenario described above, while, under the crisis scenario, a recession similar to the recession experienced in 2008-09 is simulated, that is, a real GDP growth rate of 1.5 percent in year 1 , followed by a mild increase to 2.5 percent in year 2 . We assume an especially sharp decline in manufacturing, which is immediately affected by the downturn. Overall inflation is projected to remain at current levels $(8.0$ percent and 7.5 percent in year 1 and year 2, respectively), but this is mainly explained by a relatively large rise in food prices. Food price inflation is expected to increase to 9.8 percent in year 1, but slightly decline in year 2, to 9.5 percent. The population and labor market projections are similar to those in the scenarios analyzed above. 
Poverty only increases slightly under this crisis scenario (figure 23). Similar to the simulation above, the poverty rate declines from 13.7 percent in 2011 to 11.7 percent in year 2 under the benchmark scenario. Assuming a crisis similar to the 2008-09 crisis, poverty rates rise to 13.5 percent in year 1 , followed by a slight decline to 12.9 percent in year 2 . This increase represents a poverty rate that is, on average, 1.1 percent higher than it would have been in the absence of the simulated macroeconomic shocks, but still lower than the 2011 rate. Moreover, the simulated poverty rate in year 2 under a crisis similar to that of the 2008-09 crisis is 2.3 percent lower than the rate simulated under a crisis scenario similar to the Argentine crisis. In addition, this crisis scenario has a small effect on income inequality (figure 24).

Figure 23

Impact of the crisis on poverty

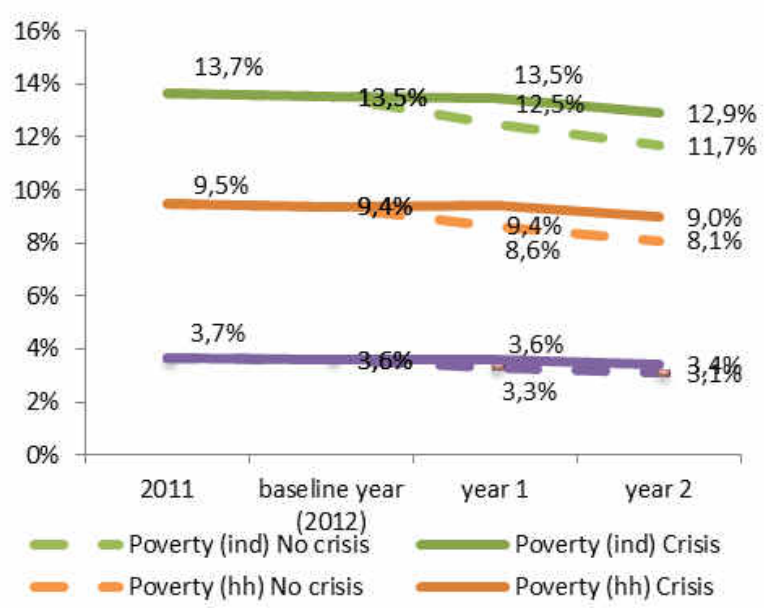

\section{Figure 24}

Impact of the crisis on inequality

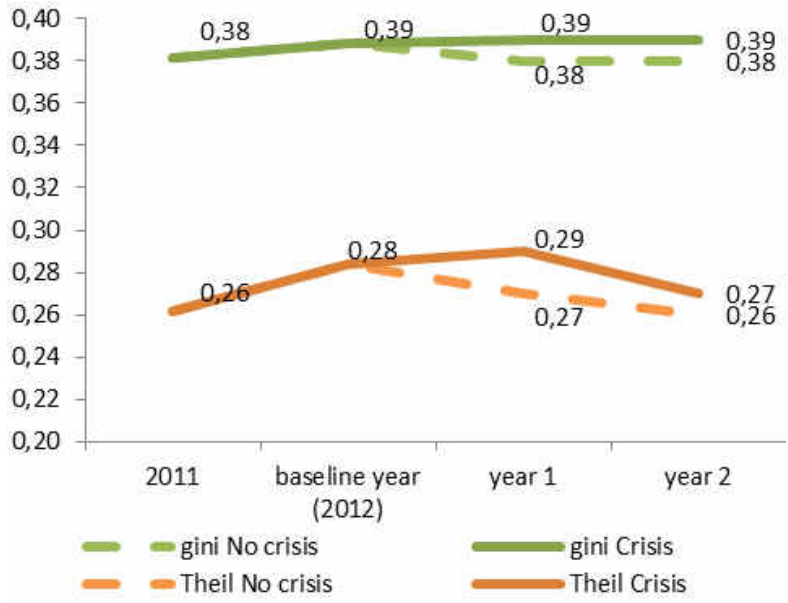

Source: World Bank calculations based on data of the ECH 2011.

The lack of growth is the main driver of the increments of the poverty rate in urban and rural areas under the crisis scenario. The results of the Datt and Ravallion (1992) decomposition in year 2 show that the higher poverty rates have mainly been caused by lower growth rather than distributional effects (figure 25). However, in urban areas and nationwide, if we take into account only the effect of negative growth, we would understate the rise in moderate poverty because the redistribution of income tends to increase the poverty rate. In rural areas, however, if we ignore the redistribution of income, we would overstate the rise in the poverty rate.

Figure 25

Datt-Ravallion decomposition: benchmark vs. crisis scenario, year 2, \% change

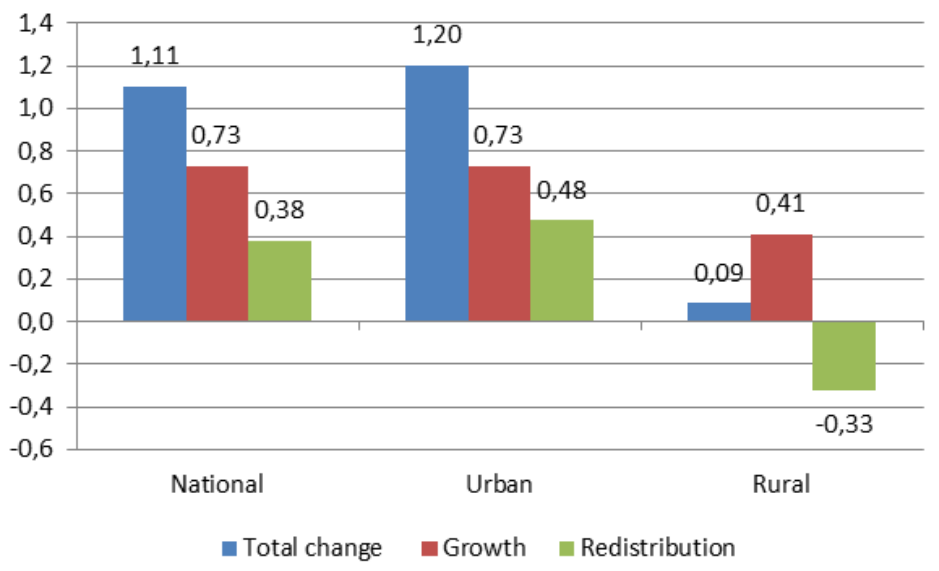

Source: World Bank calculations based on data of the ECH 2011. 


\section{POLICIES TO PROTECT THE VULNERABLE FROM FALLING BACK INTO POVERTY}

\subsection{How Uruguay responded after the 2001-02 crisis}

Given the large number of people who fell into poverty during the 2001-02 crisis, one of the biggest challenges facing Uruguay in the past decade was postcrisis recovery. Several important social programs were implemented or expanded following the 2001-02 crisis (see above). Prior to the crisis, the existing family allowance program, Asignaciones Familiares, created in 1943, provided monthly cash benefits to formal sector workers with children (Amarante and Vigorito 2012). Previously, a social pension scheme had been implemented in 1919 for the elderly and disabled, targeting socially vulnerable people. Pensions were indexed to the national average wage in 1989, causing government expenditures to increase, along with economic growth. These transfers were protected during the crisis in 2002, but were not raised. Given the significant decline in household income discussed above, Asignaciones Familiares was expanded in 2004 to include households with incomes less than $\$ 39$ a month (three times the national minimum wage), but the benefits provided were low; so, there was not a strong short-term reduction in poverty.

Recognizing the need for additional assistance to the poor to facilitate social inclusion, the PANES program was implemented between April 2005 and December 2007 to target the bottom 20 percent of households living below the poverty line ( 8 percent of the total population). The plan had four main components: a cash transfer, a food card, educational and social reinsertion programs, and housing subsidies and public works. Of the households that were selected to participate, almost all received the cash transfer; 80 percent received the food card; and 20 percent participated in the last two components. PANES covered 83,000 households ( 5 percent of all households and 10 percent of the population) and represented 30 percent of the household incomes among the beneficiaries. The cost of the program was $\$ 80$ million annually, which represented 0.41 percent of GDP during the period.

To complement the launch of PANES, the Ministry of Social Development was established as an organization of social protection and to coordinate all government benefits. This organization has come to represent an important effort at the centralization of government-provided protection and has boosted the efficiency of such benefit programs. This was a vital step, given the difficulties typically encountered in the creation and administration of social welfare programs in developing countries and emerging markets.

After the end of PANES, because poverty rates were still high, there was a transition to the Asignaciones Familiares-Plan de Equidad. This equity plan included tax and health care reforms, continued the family allowance $(\$ 8-\$ 16$ in cash transfers per child among households that did not receive the national minimum salary), continued the food card program, expanded the coverage of early childhood services, and lowered the retirement age (see below). There were 364,000 beneficiaries of the plan, which covered 76 percent of all destitute children and 68 percent of children living in poverty (2009 data), accounting for almost all households in the poorest quintile. As a result, there was a 30 percent reduction in the incidence of poverty and a 7 percent decrease in the poverty gap. There was also an expansion in secondary-school enrolments, but also in informality, given that households did not want to cross the income threshold to lose the benefit. This is a consequence that must be taken into account in future policy discussions (see above).

\subsection{Policy options to protect the poor and vulnerable against the next crisis}

Uruguay has recovered from a crisis in recent years, and most of the population is moving into the middle class and into the economic group vulnerable to fall back into poverty, which corresponds to the group of people living on \$4-\$10 a day (at 2005 international U.S. PPP dollars) 
(López-Calva and Ortiz-Juárez 2014). A fundamental question for policy makers and international organizations focused on poverty mitigation in Uruguay and other developing countries and in emerging markets is therefore how to target scarcer resources to protect poor and vulnerable households more effectively against the risk of poverty.

One of the key goals of a successful social policy is to give the vulnerable tools to ensure that they do not fall back into poverty in the event of another crisis. The indirect impacts of policy programs are particularly important if we consider that the impacts of crises on the poor are not generally restricted to the short run, a concept Fiszbein, Kanbur, and Yemtsov (2014) call the cost of risk. In fact, the short-term ways in which households cope with risks (perhaps pulling children out of school, for example) can be highly detrimental in the long term. Accordingly, it may be difficult to judge the success or failure of a short-term program because the medium-term effects are more difficult to assess, but may be even more important.

According to Kanbur (2010), crises should be viewed as the new normal in developing economies, that is, they will be systematic and should be expected, although both the timing and nature of the crises (which is related to the cause) may be unknown ex ante. Hence, there must be mechanisms in place beforehand for effective coping. Moreover, crises affect countries differently. Thus, small economies are especially vulnerable because of their substantial dependence on the effect of a crisis on their larger neighbors and the responses of these neighbors to a crisis, as seen in the case of Uruguay with respect to Argentina and Brazil in 2001-02. However, policy makers also face known problems of adverse selection and moral hazard in the design and implementation of programs as well as additional political difficulties in scaling down the intervention after a crisis.

Kanbur (2012) therefore proposes the idea of stress testing a system against a range of potential crises to identify gaps in coverage and areas where flexibility might need to be improved. Once this step is complete, he proposes devoting resources to addressing the holes and to offer a "prequalified line of assistance for social protection, which would be available to a country immediately when previously agreed upon crisis triggers are breached" (Kanbur 2012, 50). The most important point is to improve flexibility in policy design and implementation to target the poor more effectively and facilitate scaling down. For example, in the often-referenced case of Mexico's Progresa-Oportunidades conditional cash transfer (CCT) program, parents received payments if their children were in school, on the idea that they would no longer need to pull them out of school during a crisis as a risk-coping mechanism. Another example is the case of Mexico during the 2008-09 crisis, when the government took advantage of the flexibility of available passive labor market policies and allowed expanded withdrawal from contributory pension savings accounts among unemployed workers and extended the coverage of health care and maternity benefits among unemployed workers who were contributers to the social security system. These were temporary measures that protected workers and their families during the worst periods of the crisis (Freije, López-Acevedo, and Rodríguez-Oreggia 2011).

In addition to higher flexibility in policy design, other options would involve building mechanisms into existing safety nets so that they support the people who are highly vulnerable to fall into poverty. For instance, de Janvry, Sadoulet, and Vakis (2010) present three areas of special government attention for the potential expansion of existing or new CCT programs to give them an extended insurance function: (1) the eligibility of beneficiaries, (2) program effectiveness, and (3) financial sustainability.

Another option involves more profoundly redesigning existing programs to address simultaneously the differentiated structural and transient causes of poverty and of the vulnerability to fall back into poverty. In particular, new interventions should aim for a gradual shift in resources and incentives from CCT programs toward interventions that could create more permanent sources of income, for instance, programs that focus on building the assets of the poor and vulnerable through transfers for productive purposes such as the purchase of equipment or training in business-related topics. 


\section{CONCLUSIONS}

During the 2001-02 Argentine crisis, Uruguay's economy suffered significantly, entering a recession and experiencing a doubling in poverty rates and substantially rising unemployment rates. The recovery from the crisis took almost a decade. In this paper, we analyze how the Uruguayan economy today would fare facing a similar to the 2001-02 crisis. We use microsimulation techniques that link macro- and microeconomic variables to assess the impact of low growth and high inflation on poverty, income inequality, and shared prosperity, taking into account household characteristics.

This approach allows us to overlap the macroeconomic effects of a crisis with the current composition of household income to reveal how the new earning composition will be affected under the crisis scenario. This exercise provides an interesting outlook on how well the reforms of the social protection system implemented in the years following the 2001 crisis are protecting vulnerable groups. However, it has not been possible for us to identify how each new program or program modification contributes individually to shield households from shocks. This is an interesting research question, which, though beyond the scope of our study, should be investigated by a future study. Nonetheless, our results allow us to shed light on the population groups that show higher levels of vulnerability under the current social protection regime and therefore should be targeted first in case new policies are implemented to respond to a new crisis.

The simulation exercise suggests that Uruguay is now in a better place to weather a severe crisis. Because of the 2001-02 crisis, the poverty rate rose from 18.3 percent in 2001 to 39.9 percent in 2004. In the simulated crisis, the poverty rate increases by only 1.5 percent (from 13.7 percent in 2011 to 15.2 percent in year 2). Moreover, in the simulation exercise, the unemployment rate rises from 6 percent in 2011 to 9 percent in year 2, while, during the Argentine crisis, the unemployment rate reached 17 percent in 2002, up from 11 percent in 1999. A large contributing factor behind the greater resilience has been the enhanced and expanded social safety nets.

Comparing the crisis scenario and the benchmark scenario, we find a slight increase in poverty, but a significant impact on shared prosperity. The simulation exercise predicts that, in the case of a negative shock, the poverty headcount rate would be 2.9 percent higher in the crisis scenario relative to the benchmark scenario. At the household level, the poverty rate is 2.3 percent higher in the crisis scenario. Inequality remains relatively constant in both scenarios. In addition, the simulation predicts a decline of 8.8 percent in the income growth of the bottom 40 under the crisis scenario relative to the benchmark scenario. Although the lack of growth is the main underlying reason for this, income redistribution also plays a role.

We can identify four main reasons for the improved ability of the country to cope with the social effects of a macroeconomic shock. The first three are at the macroeconomic level: (1) more effective debt management, (2) better banking regulations, and (3) export diversification. The fourth reason, namely, (4) an improved social safety net, directly affects households by reducing their exposure to shocks. In relation to this last reason, even though Uruguay has one of the oldest social protection systems in the region, new policies were implemented only after the 2001-02 crisis to expand coverage to groups traditionally marginalized from the system. In particular, noncontributory programs were expanded for households with children that are not part of the formal labor market and that are especially affected by shocks.

The targeting of social programs on groups that have been historically vulnerable has played a key role in enhancing the resilience of these groups in the face of crises, in particular, by exercising positive effects that are not limited to increases in income, but also include improvements in dwelling materials, capital accumulation, and a greater medium-term capacity to generate new income. (Rofman 2013). At the same time, through the creation of the Ministry of Social Development, a new institutional arrangement was established to coordinate more effectively the programs already in place. 
However, despite the expanded protection for vulnerable households, our results show that almost 4 percent of the population is still vulnerable to fall back into poverty in case of a crisis. The per capita income of that group would be, on average, 30 percent lower in a crisis than in the absence of a crisis. The simulation predicts that vulnerability to poverty is positively correlated with a higher incidence of woman-headed households, larger households, and young adults with lower educational attainment than in the rest of the population. The likelihood of falling back into poverty is also greater in Montevideo than in rural areas. With respect to the previous result and taking into account that the coverage of households with children through CCT programs is already one of the more generous in the region (Fiszbein and Schady 2009), the policy response to ensuring greater protection of the poor and vulnerable from falling back into poverty during a potential future crisis should not be focused on raising the value of transfers, but on (1) improving the flexibility of program design and implementation to target the poor more effectively and to facilitate scaling down, (2) building mechanisms into existing safety nets so that these can expand the support available to highly vulnerable people who may fall into poverty, and (3) redesigning existing programs to address simultaneously the differentiated structural and transient causes of poverty and the vulnerability of falling back into poverty, while creating programs aimed at population groups currently underserved by the system, such as households composed of young adults with no children.

\section{Acknowledgements}

An earlier version of this manuscript has been published as Is Uruguay more resilient this time? distributional impacts of a crisis similar to the 2001/02 Argentine crisis by The World Bank in the Policy Research Working Paper No. WPS6849, 2014.

\section{References}

Amarante, Verónica, and Andrea Vigorito. 2012. "The Expansion of Non-Contributory Transfers in Uruguay in Recent Years.” Policy Research Brief 29, International Policy Centre for Inclusive Growth, Brasília, Brazil.

Bourguignon, François, Maurizio Bussolo, and Luiz A. Pereira da Silva. 2008. "Introduction: Evaluating the Impact of Macroeconomic Policies on Poverty and Income Distribution." In The Impact of Macroeconomic Policies on Poverty and Income Distribution: Macro-Micro Evaluation Techniques and Tools, edited by François Bourguignon, Maurizio Bussolo, and Luiz A. Pereira da Silva, 1-23. Washington, DC: World Bank; New York: Palgrave Macmillan.

Cotlear, Daniel, ed. 2011. Population Aging: Is Latin America Ready? Report 58842. Directions in Development: Human Development. Washington, DC: World Bank. doi: 10.1596/978-0-8213-8487-9.

Datt, Gaurav and Martin Ravallion. 1992. "Growth and Redistribution Components of Changes in Poverty Measures: A Decomposition with Applications to Brazil and India in the 1980s." Journal of Development Economics 38 (2): 275-95. doi:10.1016/0304-3878(92)90001-P.

de Janvry, Alain, Elisabeth Sadoulet, and Renos Vakis. 2010. "Protecting Vulnerable Children from Uninsured Risks: Adapting Conditional Cash Transfer Programs to Provide Broader Safety Nets." Well-being and Social Policy 6 (1): 161-83.

Estrades, Carmen, and Cecilia LLambí. 2013. "Lessons from the 2008 Financial Crisis: Policy Responses to External Shocks in Uruguay.” Developing Economies 51 (3): 233-59. doi: 10.1111/deve.12017.

Ferreira, Francisco H. G., Phillippe G. Leite, Luiz A. Pereira da Silva, and Paulo Picchetti. 2008. "Can the Distributional Impacts of Macroeconomic Shocks Be Predicted?: A Comparison of Top-Down MacroMicro Models with Historical Data for Brazil." In The Impact of Macroeconomic Policies on Poverty and Income Distribution: Macro-Micro Evaluation Techniques and Tools, edited by François Bourguignon, Maurizio Bussolo, and Luiz A. Pereira da Silva, 119-74. Washington, DC: World Bank; New York: Palgrave Macmillan. Book?

Fiszbein, Ariel, Ravi Kanbur, and Ruslan Yemtsov. 2014. "Social Protection and Poverty Reduction: Global Patterns and some Targets." World Development 61 (1): 167-177. doi:10.1016/j.worlddev.2014.04.010. 
Fiszbein, Arial, and Norbert Schady. 2009. Conditional Cash Transfers: Reducing Present and Future Poverty. Report 47603. World Bank Policy Research Reports. With Francisco H. G. Ferreira, Margaret Grosh, Niall Keleher, Pedro Olinto, and Emmanuel Skoufias. Washington, DC: World Bank. doi: 10.1596/978-0-8213-7352-1.

Foster, James, Joel Greer, and Erik Thorbecke. 1984. “A Class of Decomposable Poverty Measures.” Econometrica 52 (3): 761-66. doi: 10.2307/1913475.

Freije, Samuel, Gladys López-Acevedo, and Eduardo Rodríguez-Oreggia. 2011. "Effects of the 2008-09 Economic Crisis on Labor Markets in Mexico.” Policy Research Working Paper 5840, World Bank, Washington, DC. doi: 10.1596/1813-9450-5840.

Gasparini, Leonardo, Sebastián Galiani, Guillermo Cruces, and Pablo Acosta. 2011. "Educational Upgrading and Returns to Skills in Latin America: Evidence from a Supply-Demand Framework, 1990-2010.” Working Paper 127, Center for Distributive, Labor, and Social Studies, Facultad de Ciencias Económicas, Universidad Nacional de La Plata, La Plata, Argentina. doi: 10.1596/1813-9450-5921.

Habib, Bilal, Ambar Narayan, Sergio Olivieri, and Carolina Sánchez-Páramo. 2010a. “Assessing Ex Ante the Poverty and Distributional Impact of the Global Crisis in a Developing Country: A Micro-Simulation Approach with Application to Bangladesh.” Policy Research Working Paper 5238, World Bank, Washington, DC. doi: 10.1596/1813-9450-5238.

2010b. "Assessing Poverty and Distributional Impacts of the Global Crisis in the Philippines: A Microsimulation Approach.” Policy Research Working Paper 5286, World Bank, Washington, DC. doi: 10.1596/1813-9450-5286.

—. 2010c. "The Impact of the Financial Crisis on Poverty and Income Distribution: Insights from Simulations in Selected Countries.” PREM Economic Premise 7 (March), Poverty Reduction and Economic Management Network, World Bank, Washington, DC.

INE (National Institute of Statistics). 2006. Líneas de Pobreza e Indigencia 2006, Uruguay: Metodología y Resultados. Montevideo, Uruguay: INE.

Kanbur, Ravi. 2010. "Protecting the Poor against the Next Crisis.” Distinguished Lecture Series, April, Egyptian Centre for Economic Studies, Cairo.

2012. "Stress Testing for the Poverty Impacts of the Next Crisis." In Knowing, When You Do Not Know: Simulating the Poverty and Distributional Impacts of an Economic Crisis, edited by Ambar Narayan and Carolina Sánchez-Páramo, 50-55. World Bank Studies 66237. Washington, DC: World Bank.

López-Calva, Luis F., and Nora Lustig, eds. 2010. Declining Inequality in Latin America: A Decade of Progress?. New York: United Nations Development Programme; Baltimore: Brookings Institution Press.López-Calva, Luis F., and Eduardo Ortiz-Juárez. 2014. "A Vulnerability Approach to the Definition of the Middle Class." Journal of Economic Inequality 12 (1): 23-47. doi:10.1007/s10888-012-9240-5.

Rofman, Rafael, ed. 2013. Hacia un Uruguay más equitativo: Los desafíos del sistema de protección social. Montevideo, Uruguay: World Bank.

World Bank. 2005. Uruguay: Sources of Growth, Policies for the Development of Human Capital, Integration, Competition, and Innovation. Report 31737-UY (June 14). Washington, DC: World Bank.

_. 2012. "Potential Impact of a Global Economic Slowdown: The Uruguayan Case." Internal briefing note, World Bank, Washington, DC.

—. 2013. "La Evolución de la Pobreza, la Desigualdad y la Movilidad de Ingresos en Uruguay durante la Década del 2000." Internal briefing note, World Bank, Washington, DC.

—. ADePT Crisis Module. Test Version. Other modules of the ADePT software http://worldbank.org/adept. 


\section{ANNEXES}

\section{A: DATA APPENDIX}

Table A.1

Poverty measures

\section{Monetary poverty: official measure}

Poverty Moderate poverty: share of the population living in households in which the per capita income is measures below the total value of the food and nonfood baskets.

Extreme poverty: share of the population living in households in which the per capita income is below the value of the food basket.

Poverty Moderate poverty line: official poverty lines depend on a food component, $C B A_{p c}$, and a nonfood lines component, $C B N A_{p c}$, following the formula for the household-specific poverty line, that is

$$
C B A_{p c} * N+C B N A_{p c} * N^{0.8}
$$

where $N$ is the number of household members.

Because the weight of the nonfood component decreases as the number of members increase, the average household per capita poverty line in Montevideo is equivalent to Ur\$239 (2012 pesos) or \$9.13 2005 PPP U.S. dollars per capita per day.

The line's values differ greatly across regions: a household in an interior urban area needs only $\$ 6.20$ 2005 PPP U.S. dollars per capita per day so as not to be considered poor, while a household in rural areas needs only $\$ 4.26$ per capita per day.

Extreme poverty line: official poverty lines follow the formula:

$$
C B A_{p c} * N
$$

To be considered not poor under this poverty line, a household in Montevideo in 2012 needed Ur\$69 per capita per day or $\$ 2.602005$ PPP U.S. dollars per capita per day. The extreme poverty line also varies across regions, but to a lesser extent. Thus, a household in an interior urban area needs only $\$ 2.44$ per capita per day not to be considered among the extreme poor, while a household in rural areas needs $\$ 2.10$ per capita per day.

For a detailed explanation of the poverty methodology, see INE (2006).

Welfare Welfare is measured by per capita household income, which, in this case, includes labor income, measure transfers, pensions, imputed rent, and capital income. Because official income cannot be completely constructed from this source, we constructed an adjusted vector. It replicated official poverty numbers.

If an indicator is required that uses data previous to 2006, we used only Montevideo and interior urban areas so as to guarantee sample comparability.

Conversion The conversion relies on the deflation of regional prices to Montevideo prices based on a ratio of to real average poverty lines. The resulting values are then converted to 2005 prices using CPI values. values

Data source ECH 2003-11; Banco Central del Uruguay; Banco de Previsión Social.

\section{B: VALIDATION OF RESULTS}

To validate the accuracy of the simulations, we have used the observed trends in macroeconomic variables for 2008-10 and 2011 to simulate the poverty headcount and poverty gap and the 2008 $\mathrm{ECH}$ dataset as the microeconomic input. Figure B.1 shows the poverty rate and the poverty gap in 2008 and the related observed and simulated trends in 2010 and 2011. As one may observe, 
the model tends to underestimate the reduction of the poverty headcount and poverty gap caused by growth and shows a bias that increases over time, increasing from a difference in the poverty headcounts of 1.8 percent in 2010 between the observed and the estimated rate to a difference of 5.4 percent in 2011.

\section{Figure B.1}

Validation of poverty results using the $2008 \mathrm{ECH}$

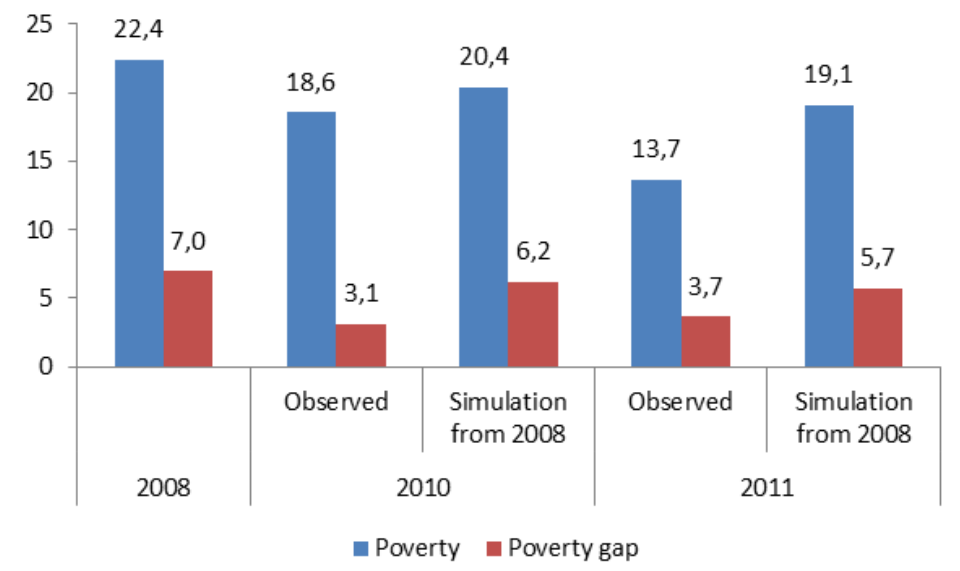

Source: World Bank calculations based on data of the ECH 2011.

To help clarify the level of adjustment of the model, chart a, figure B.2 shows the DattRavallion decomposition between the poverty rate observed in 2011 and the poverty rate simulated by the model. The difference of 5.4 percent between the simulated scenario and the actual value is driven mainly by growth: two-thirds of the difference is explained by differences in the estimated growth rate of the mean, and one-third by the distribution of this growth rate. The results shown in chart a, figure B.2 can be interpreted more readily if we take the information in chart b, figure B.2 into account. The latter chart displays the difference between the simulated growth in 2008-10 and 2011 and the observed growth during the same period. The model tends to underestimate growth at the bottom of the distribution and to overestimate growth among the top 5 percentile, which, hence, results in the differences in poverty rates described above (figure B.1) and the negative distribution effect shown in chart a, figure B.2. This gap between the estimated and observed incomes is larger in 2011.

Figure B.2

Difference between observed and estimated incomes

a. Datt-Ravallion decomposition (2011): observed vs. simulated

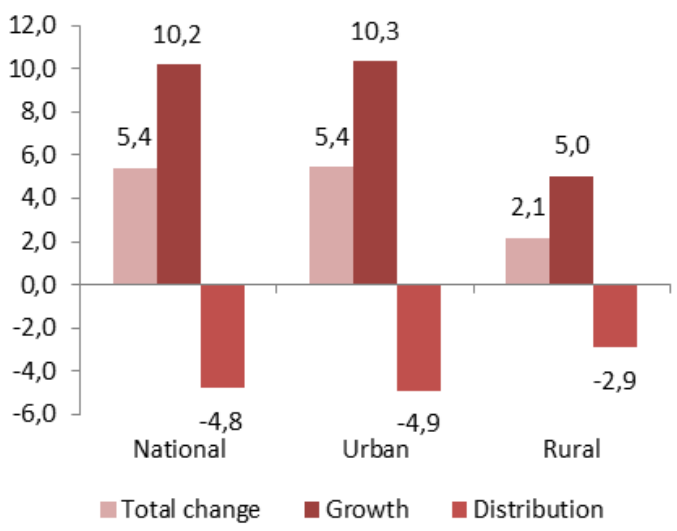

b. Difference between observed and estimated incomes

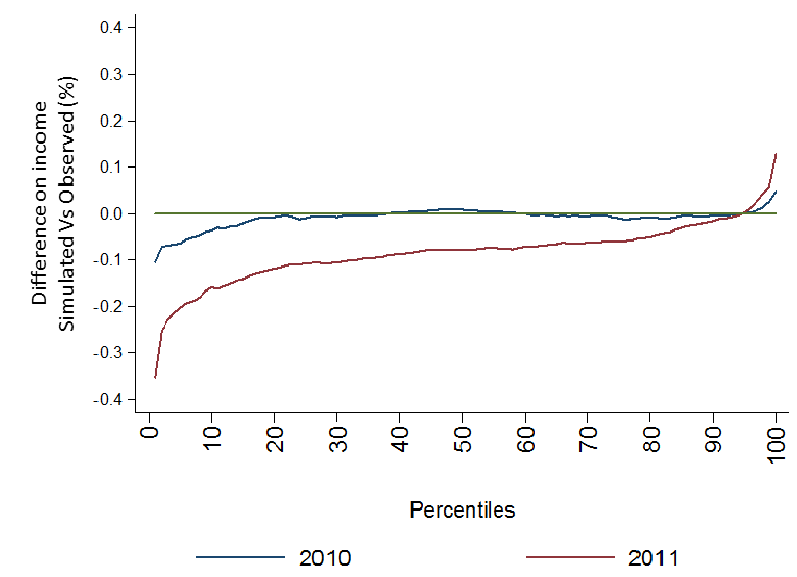

Source: World Bank calculations based on data of the ECH 2010-11. 